\title{
Inclusión de la variable espacial en la medición de las condiciones relativas de vida en ciudades mexicanas
}

\section{Inclusion of the spatial variable in the measurement of relative living conditions in Mexican cities}

\author{
Juan Campos-Alanís, ${ }^{*}$ Luis Giovanni Ramírez-Sánchez** \\ Carlos Garrocho** \\ *Facultad de Geografía, Universidad Autónoma del Estado de México, México \\ **El Colegio Mexiquense A.C., México
}

Resumen

\begin{abstract}
Los métodos más utilizados para medir las condiciones relativas de vida de la población (CRV) (e.g. marginación, pobreza, rezago social, desarrollo humano), han sido base para el diseño de políticas sociales en México y varios países de Latinoamérica. Estos métodos predominantes excluyen el papel activo del espacio como distribuidor y redistribuidor de oportunidades de bienestar derivadas de servicios públicos estratégicos de localización puntual (e.g. servicios de educación y salud). Omiten el hecho fundamental de que la oferta y la demanda de estos servicios deben interactuar en el territorio para generar beneficios: como si las CRV se moldearan en un no-lugar (Campos, 2009). El paradigma de Justicia Espacial incorpora al espacio como un agente redistributivo clave de recursos y oportunidades entre la sociedad (Soja, 2014). Los objetivos de este trabajo son: i) proponer, a partir del paradigma de la Justicia Espacial, un método de medición de las CRV que incorpore auténtica y operativamente la dimensión espacial; y, ii) demostrar la superioridad conceptual, analítica y aplicada de nuestro método Socioespacial para medir las CRV, respecto a los métodos tradicionales No-Espaciales.
\end{abstract}

Palabras clave: Condiciones relativas de vida, accesibilidad, justicia espacial.

Abstract

The most widely used methods to measure the relative living conditions of the population (CRVs) (e.g. marginalization, poverty, social deprivation, human development), have been the basis for the design of social policies in Mexico and several Latin American countries. These predominant methods exclude the active role of space as a distributor and redistributor of welfare opportunities derived from strategic public services located in specific points in the territory (e.g. education and health services). They omit the basic fact that the supply and demand of these services must usually interact in the territory to generate benefits. As if the CRVs were molded in a non-place (Campos, 2009). The Spatial Justice paradigm incorporates space as a key redistributive agent of resources and opportunities among society (Soja, 2014). This work has the following objectives: i) Propose, from the paradigm of Space Justice, a method of measuring CRVs that authentically and operationally incorporates the spatial dimension; and, ii) demonstrate the conceptual, analytical and applied superiority of our Socio-spatial method to measure the CRVs, with respect to traditional Non-Spatial methods.

Keywords: Relative living conditions, accessibility, spatial justice. 


\section{INTRODUCCIÓN}

D

isciplinas como la economía, demografía, sociología y la ciencia política, entre otras, han elaborado valiosas aportaciones para el estudio de múltiples temáticas relacionadas con el estudio de las condiciones relativas de vida de la población (CRV). Sobre todo, en términos de mediciones de pobreza, exclusión social, marginación y desarrollo humano. Sin embargo, una debilidad común de los enfoques dominantes (tradicionales) es que sus métodos para cuantificar las CRV han excluido el papel del territorio como un agente activo en la redistribución socioespacial de las oportunidades y los recursos (tanto públicos como privados) (ÁlvarezLobato et al., 2018).

El paradigma de la justicia espacial incorpora al espacio como un elemento clave que afecta las CRV y utiliza una serie de atributos que facilitan la comprensión de su rol redistributivo de oportunidades y recursos entre grupos sociales y territorios (Soja, 2014). Por ejemplo, la magnitud y distribución espacial de la oferta y la demanda de bienes y servicios (e.g. salud, educación) así como de otras oportunidades de bienestar (e.g. empleo, abasto), la accesibilidad que facilita o inhibe la interrelación de la oferta y la demanda en el territorio, las características físicas del espacio geográfico (e.g. topografia del terreno).

Estos y otros elementos de carácter territorial influyen en el aprovechamiento de las oportunidades de bienestar que se ofrecen a la población en ciudades y regiones (Kaztman, 1999; 2005). Por tanto, el paradigma de la Justicia Espacial puede ser una alternativa para complementar los enfoques tradicionales No-espaciales, con el fin de estimar con mayor precisión las CRV vinculadas a la disponibilidad de oportunidades de bienestar de localización puntual (e.g. salud, educación, empleo, abasto) y diseñar políticas públicas más realistas, focalizadas y eficaces.

Los objetivos de este trabajo son: i) proponer, a partir del paradigma de la justicia espacial, una metodología que incorpore auténtica y operativamente la dimensión espacial para la estimación de las CRV de la población, vinculadas a oportunidades de bienestar de localización puntual; y, ii) demostrar la superioridad conceptual, analítica y aplicada de nuestro enfoque respecto a los métodos tradicionales (No-espaciales) de medición de las CRV. Para ello se propone tomar como caso de estudio la quinta metrópoli más importante del país y de la cual se tiene pleno conocimiento: Toluca, se utilizan fuentes de información del Censo de Población y Vivienda del 
Inclusión de la variable espacial en la medición de las condiciones relativas de vida en ciudades ... / J.CAMPOS ALANÍS et al.

2010 a escala de sección electoral y el análisis estadístico y espacial se realizó con software especializado.

La premisa de partida de nuestro trabajo es cardinal: las metodologías que reporta la literatura para medir las CRV son No-espaciales, pues sólo reflejan la condición del lugar donde se capta la información. Por ejemplo: se obtiene información sobre si la población dispone o no de servicios de salud (e.g. la cobertura administrativa o normativa de un servicio en el lugar), pero no se considera la accesibilidad de ese servicio para la población (la facilidad de acceder y utilizar adecuadamente el servicio). Como si el espacio no mediara la utilización suficiente y oportuna de los servicios (e.g. el aprovechamiento apropiado de las oportunidades de bienestar: Garrocho y Campos, 2006). ${ }^{1}$

Los enfoques tradicionales No-espaciales omiten que la oferta y la demanda de servicios deben interrelacionarse en el espacio (particularmente de aquellos que se ofrecen en puntos específicos del territorio, como los de educación y salud) y que la intensidad y eficacia de estas interacciones dependen, en gran parte, de diversos factores espaciales que discriminan y relegan a algunos y benefician y privilegian a otros (e.g. costos de transporte, movilidad del servicio y de los consumidores). En otras palabras, los enfoques tradicionales No-espaciales de medición de las CRV asumen un contexto a-dimensional que no existe en la realidad cotidiana de aquello que tratan de medir. Ni más, ni menos.

En contraste, la propuesta metodológica que se hace en este trabajo, considera que la población vive su realidad cotidiana en un contexto espacial específico, por lo que resulta primordial incorporar la accesibilidad a las oportunidades de bienestar (e.g. servicios, empleo, abasto) en la medición de las CRV. ${ }^{2}$ Este es el punto central de nuestra propuesta: en lugar de considerar solamente la presencia (cobertura normativa o administrativa) o ausencia de servicios en una cierta unidad espacial (como lo hacen las metodologías del Programa de Naciones Unidas para el Desarrollo, Banco

\footnotetext{
'Lo que Ramos y Garrocho (2019) llaman "calidad de consumo", definido como "la adecuada cantidad, frecuencia y oportunidad del consumo". Cantidad adecuada significa que el bien o servicio se consume en la cantidad correcta o necesaria de acuerdo con las condiciones de la persona y a los estándares de los especialistas. Frecuencia adecuada se refiere a evitar la sub o sobreutilización de un servicio o bien. Oportunidad adecuada implica que se recibe el servicio o bien en el momento más conveniente para la persona. El concepto de "calidad de consumo" matiza el principio de la microeconomía que dice "a menor precio mayor consumo y viceversa" y expresarlo como: "a menor precio mayor calidad de consumo y viceversa".

2 Aunque Amartya Sen (1996) ya planteaba el enfoque de las oportunidades, su idea no está completamente desarrollada en el sentido de que pareciera darse por hecho que éstas existen en los lugares de residencia de la población que está siendo analizada. Esto es, omite aspectos relevantes como la localización y magnitud de la oferta y la demanda para alcanzar el desarrollo humano y los sustituye por un indicador simple de cobertura.
} 
Mundial o el Gobierno de México), nuestro método va más allá y considera que la accesibilidad a las oportunidades de bienestar no es la misma para toda la población, sino que varía en el territorio en función de: i) la magnitud de la oferta de servicios; ii) la magnitud de la demanda; y iii) los costos de transporte que deben sufragar los usuarios para recibir los servicios. Justo aquí radica la aportación de este trabajo: incorporar el espacio a la medición de las CRV a fin de hacer más robustos los indicadores comúnmente utilizados para identificar la población objetivo de políticas sociales. Es de suponer que contar con índices territorializados de las CRV permitirá reconceptualizarlas con visión socioespacial, realizar mediciones y análisis más realistas y diseñar políticas públicas más eficaces.

La estrategia de nuestra argumentación es la siguiente: en los antecedentes teóricos y empíricos incluimos una revisión condensada de los dos paradigmas dominantes en México —uno de ellos prevalece incluso en Latinoamérica ${ }^{3}$ - para el estudio de las CRV, que son la marginación socioeconómica y el enfoque de desarrollo humano. El propósito es develar las debilidades inherentes a su perspectiva No-espacial. Luego, dirigimos los reflectores al enfoque de justicia espacial, con el propósito de aislar sus principales planteamientos y elementos que nos ofrezcan soporte teórico, específicamente a los vinculados a lo que llamamos justicia distributiva de oportunidades de bienestar. Después, resolvemos el dilema de cómo incorporar conceptualmente la dimensión espacial en las mediciones de las CRV. Para esto retomamos los conceptos de accesibilidad y calidad urbana (Garrocho y Campos, 2006; Campos y Garrocho, 2018). Una vez que contamos con un enfoque teórico suficiente, nos abocamos a traducirlo en una metodología robusta y replicable, por lo que explicamos en detalle cómo ponerla en práctica. En la sección de resultados hacemos un análisis de contraste entre las mediciones de CRV que se generan con el enfoque tradicional No-espacial y con nuestro enfoque Espacial. Para hacer esta prueba seleccionamos la quinta metrópoli más poblada de México (la Zona Metropolitana de Toluca). Finalmente, sintetizamos los hallazgos y extraemos algunas conclusiones.

\footnotetext{
${ }^{3}$ El abordaje a nivel latinoamericano dependería en gran parte de los insumos cartográficos y fuentes de información a diversas escalas, disponibles en los diferentes países latinoamericanos. Una prueba de su aplicabilidad puede revisarse en Pérez (2015), donde se utiliza una variante del método propuesto en 2006 por dos de los autores de este artículo, aplicado en Barranquilla, Colombia.
} 
Inclusión de la variable espacial en la medición de las condiciones relativas de vida en ciudades ... / J.CAMPOS ALANIS et al.

\section{ANTECEDENTES TEÓRICOS Y EMPÍRICOS}

En este apartado se hace una breve revisión de los métodos de medición de las CRV más relevantes para este trabajo: el Índice de Desarrollo Humano (IDH) que utiliza el Programa de Naciones Unidas para el Desarrollo (PNUD), con el fin de asegurar comparaciones internacionales, y el Índice de Marginación (IM), que se utiliza en México para identificar unidades espaciales (e.g. estados, municipios, localidades, zonas urbanas, manzanas) que registran una serie de carencias vinculadas a la cobertura de servicios a la población y en las viviendas. El IDH es quizá el más reportado en la literatura internacional, mientras que el IM ha sido base para seleccionar los beneficiarios de la mayoría de las políticas sociales en México. Ambos están entre los que consideramos enfoques tradicionales No-espaciales para la medición de las CRV. La breve revisión de estos métodos tiene dos objetivos centrales: $i$. demostrar que ambos relegan el papel clave del territorio como distribuidor socioespacial de las oportunidades de bienestar; $\mathrm{y}$, ii. preparar la revisión del fundamento conceptual de nuestro método espacial.

\section{La propuesta de Desarrollo Humano del Banco Mundial}

Amartya Sen (1996: 56) es el principal filósofo de esta corriente que apunta al desarrollo de las capacidades y libertades de las personas como condición para lograr su progreso. La capacidad es la habilidad de los individuos para lograr alguna meta propuesta a partir de una combinación de funcionamientos, entendidos como partes del estado de una persona que logra realizaciones en términos de ser y hacer (e.g. para realizar su plan de vida). Para lograr las realizaciones, Sen establece el concepto de oportunidades, pues sin ellas de nada sirve tener las capacidades (e.g. el nivel de escolaridad otorga la capacidad de emplearse en un determinado trabajo, pero también se requiere que existan oportunidades (London y Santos, 2007).

Estos planteamientos los retomó el PNUD y el IDH, que se apoya en tres indicadores estratégicos: i) longevidad (calculada mediante la esperanza de vida al nacer); ii) logro educacional (a través de la alfabetización de adultos y la matrícula combinada de varios niveles educativos); y, iii) nivel de vida mediante el PIB per cápita anual ajustado (paridad del poder adquisitivo en dólares). Con estos indicadores, el PNUD intenta medir el progreso socioeconómico de casi todos los países del mundo.

Como se puede apreciar en los indicadores propuestos por el IDH, la dimensión espacial está ausente, por ejemplo, en el logro educacional, que 
tiene implícitos una serie supuestos cuestionables donde en la unidad de análisis (e.g. ciudad, región, país) existen las instalaciones de educación necesarias y suficientes para brindar el servicio o que la gente tiene la misma capacidad de acceder a ellas. Este segundo supuesto es particularmente relevante para nosotros, porque el costo para trasladarse del lugar de residencia al lugar donde se ofrece el servicio puede ser la gran diferencia entre utilizarlo o no, ahí se nota claramente la ausencia del componente espacial.

\section{El indicador de Marginación Socioeconómica de México}

En México, la Coordinación General del Plan Nacional de Zonas Deprimidas y Grupos Marginados (COPLAMAR) realizó los primeros estudios sobre la geografía de la marginación (COPLAMAR, 1982: 22). Su enfoque partió del Método de Necesidades Básicas Insatisfechas (NBI), que retoma la definición de pobreza absoluta definida a partir de un mínimo de satisfacción de necesidades básicas de bienes y servicios (Sánchez, 2000: 47). La población marginada es aquella que tiene insatisfechas sus necesidades esenciales, que generalmente no posee medios de producción, y, si los tiene, son de bajas tecnología y productividad. Además, esta población no tiene trabajo permanente, cuenta con escasa educación y bajo acceso a información (Bennholdt, 1981; Campoy, 2002). Posteriormente, para la determinación de la marginación, se propuso un índice resumen integrado por nueve indicadores agrupados en cuatro dimensiones: educación, vivienda, distribución de la población e ingresos monetarios, los cuales se sintetizan mediante el método estadístico de componentes principales y se estratifican con el método Dalenius-Hodges (CONAPO, 2011).

\section{Debilidades clave de los métodos tradicionales No-Espaciales}

Notemos que las conceptualizaciones anteriores ignoran el componente territorial. Cuando se habla de servicios se señala si existe o no cobertura administrativa de ciertos servicios, pero en ningún momento se considera dónde se ofertan los servicios y cuáles son las dificultades o barreras para acceder a ellos (los costos de utilización). Pareciera que la marginación o el desarrollo humano ocurren en un no-lugar y, por tanto, estos enfoques omiten el papel del territorio como distribuidor socioespacial de los beneficios y costos del desarrollo. ${ }^{4}$ La omisión es grave porque la

\footnotetext{
${ }^{4}$ El desarrollo amplía la oferta de servicios (e infraestructuras) que generan beneficios, pero también costos. Estos beneficios y costos no se distribuyen homogéneamente en términos socioespaciales, sino que benefician/perjudican más a unos ciudadanos/territorios que a otros. Por ejemplo, un hospital o una terminal de autobuses generan enormes beneficios a una ciudad, pero,
} 
Inclusión de la variable espacial en la medición de las condiciones relativas de vida en ciudades ... / J.CAMPOS ALANÍS et al.

distribución permanente de oportunidades en el territorio redefine las CRV de la población.

En otras palabras, las metodologías revisadas - las más importantes en México y en varios países latinoamericanos - son inconsistentes con la realidad. La población marginada registra ciertos patrones socioespaciales bien definidos: usualmente son pobres y residen en regiones y áreas de la ciudad con poca accesibilidad espacial al bienestar (Kaztman, 2005). Los factores causales son diversos y conocidos: falta de atención política, escasez de infraestructura, limitados equipamientos y apoyos para la movilidad (que son fundamentales para utilizar diversos servicios sociales: educación, salud), topografía del territorio, asentamientos humanos dispersos y con baja densidad de población, mercados de suelo y vivienda marginadores y otros elementos que, en conjunto, dificultan que la población con menores recursos aproveche adecuadamente las oportunidades de bienestar (Kaztman, 1999; Campos, 2009). En las grandes ciudades latinoamericanas, la población pobre vive en la trampa de la localización periférica: “...donde puede vivir no tiene acceso al bienestar, donde tiene acceso al bienestar no puede vivir" (Garrocho, 2014).

En síntesis, los enfoques dominantes para medir las CRV en México y en Latinoamérica (a través del PNUD), no consideran el notable papel del espacio como distribuidor y redistribuidor socioespacial de múltiples beneficios y costos de vivir en sociedad (Garrocho y Campos, 2016). Relegan al espacio, a pesar de que es un elemento clave que amplía o reduce las capacidades y libertades de las personas para vivir dignamente, realizar su plan de vida, participar de la vida social e integrarse al desarrollo.

\section{Justicia espacial: enfoque fundamental para la medición espacial de las CRV}

El debate sobre justicia espacial es relativamente reciente. Los primeros trabajos datan de los años noventa (ver Soja, 2009), aunque sus antecedentes se remontan a la década de los setenta del siglo pasado. Son notables los trabajos seminales de Harvey (1973); Pinch (1979), Smith (1974; 1977) y Pirie (1983).

Existen varias definiciones de justicia espacial. Pirie (1983), por ejemplo, ofrece una primera aproximación y acuña el término: justicia social en el espacio, donde el espacio se entiende como producto y reproductor social, y no como un escenario irrelevante en el que simplemente ocurren los

al mismo tiempo, producen grandes incomodidades (costos o externalidades negativas: tráfico, ruido) a los vecinos. El espacio distribuye y redistribuye estos beneficios y costos. 
procesos sociales. El problema de trasladar al espacio la justicia social, es que el territorio registra diferentes realidades según la escala que se considere y según su delimitación (e.g. los famosos problemas de la unidad espacial modificable y de la falacia ecológica: Openshaw, 1984). Para Pirie, lo que importa es la distribución entre las personas de los beneficios y costos de vivir en sociedad, no las distribuciones entre territorios artificialmente delimitados.

En la planeación y en los estudios del territorio es muy frecuente la denuncia de "desigualdades espaciales" demostradas empíricamente. Sin embargo, poco se ha profundizado en la construcción de teoría socioespacial que articule conceptos, observaciones, razonamientos y métodos (Gervais-Lambony, 2007; Bromberg et al., 2007: 1-3, Soja, 2014: 45-64). En este contexto, destacan los trabajos conceptuales de Edward W. Soja, uno de los principales teóricos contemporáneos sobre justicia espacial desde una perspectiva postestructuralista (Soja se apoya en los trabajos de Harvey, 1973; Lefebvre, 1996, entre otros: Bromberg et al., 2007). A menudo se cita a Soja como quien avanza la noción de la interrelación mutua entre lo espacial y lo social. Sin embargo, esta concepción de lo socioespacial es muy anterior a sus trabajos (e.g. Pred, 1985). ${ }^{5}$ Para Soja (2014), la Justicia Espacial no es distinta a la justicia social, ya que ambas tienen las mismas características ontológicas de la vida humana: historicidad, socialidad y espacialidad (Rivas, 2012).

Quizá la aportación más importante de Soja es ahondar en el papel del espacio como productor y resultado de procesos sociales (e. g. justicia / injusticia social), aunque ya existían poderosos planteamientos al respecto antes de Soja, originados desde diversas perspectivas ideológicas (Harvey, 1973; Smith, 1994), incluso desde México (Garrocho, 1995). Así, para Soja, justicia espacial significa develar las interrelaciones mutuas entre las condiciones socioeconómicas de la población y la configuración del espacio, entendiéndolo como agente activo de esas interrelaciones. Debe notarse que en ningún momento la Justicia Espacial cae en el determinismo geográfico. Desde la perspectiva de Soja, las injusticias espaciales son producto del desarrollo desigual generado por las relaciones sociales y económicas de los modos de producción, pero también por la configuración y reconfiguración del espacio funcional que afecta y es afectado por las relaciones socioeconómicas (Brand, 2007: 2-3; Castells, 1977; Lefebvre 1996: 148-157; Soja, 2014).

Existen propuestas tendientes a traducir operativamente la idea de justicia espacial. Bosque et al. (2006: 56; 2002: 91) plantean que la justicia

\footnotetext{
${ }^{5}$ El puro título del trabajo de Allan Pred es contundente: The social becomes the spatial, the spatial becomes the social.
} 
Inclusión de la variable espacial en la medición de las condiciones relativas de vida en ciudades ... / J.CAMPOS ALANIS et al.

espacial es "el grado de igualdad en la distribución de los servicios entre la población...", por lo que no deben existir concentraciones territoriales excesivas de bienes y servicios, ya que agudizan las desigualdades sociales. Desde esta perspectiva, la idea de justicia espacial es medible de manera aproximada mediante las distancias que separan la oferta (e.g. bienes, servicios, empleo) y la demanda (e.g. la población): a menor distancia (e.g. menor costo de transporte) más justa la distribución y viceversa. Para Garrocho (1995; 1997) la justicia espacial (que llama justicia locacional) depende de la perspectiva filosófica que se adopte respecto a la justicia distributiva (Allingham, 2014). Cada perspectiva puede traducirse en una función objetivo en términos de accesibilidad y resolverse aceptablemente con una herramienta cuantitativa (e.g. modelos de localización-asignación). En este sentido su perspectiva es muy similar a la de Smith (1994). En el planteamiento de estos autores se tocan la filosofía (e.g. teorías de justicia distributiva) y los modelos matemáticos de planeación locacional, la accesibilidad y el aprovechamiento adecuado y justo de las oportunidades de bienestar.

Para nuestro trabajo, lo más relevante de los aportes de la justicia espacial, es el aprovechamiento socioespacial de las oportunidades de bienestar (Kaztman, 1999; 2005) y el cumplimiento de múltiples derechos económicos, sociales y ambientales (Soja, 2014). Para Soja es importante la participación política y plantea una concepción de la justicia espacial donde el capitalismo no es la clave de las injusticias, como sí lo es para Harvey. Soja plantea la posibilidad de lograr Justicia Espacial sin establecer como requisito cambios estructurales en el orden socioeconómico capitalista (Rivas, 2012).

La visión teórica de Soja sobre justicia espacial es muy estimulante, aunque ha sido poco exitosa en términos prácticos (Link, 2011). Así, nuestro propósito es modesto en términos conceptuales, pero innovador en cuanto a lo metodológico: incorporar la idea de justicia espacial en las mediciones de las CRV en México y Latinoamérica. Evitamos, deliberadamente, vincularnos con algún enfoque filosófico de justicia distributiva con el fin de no limitar la aplicación de nuestro método, entendemos las oportunidades de bienestar en el sentido de Kaztman (1999; 2005), y consideramos la participación política a través de la difusión del conocimiento y la inclusión del espacio en la medición de las CRV, más que como la participación activa en movimientos sociales (adoptamos una postura política a la Soja, 2009).

Es importante reconocer que una distribución absolutamente justa de oportunidades de acceso al bienestar y al desarrollo no es alcanzable en la realidad (para comenzar: ¿Qué es lo justo?; Garrocho, 1995). Cada geografía en la que vivimos 
tiene un cierto grado de injusticia inevitable, en parte por el inherente contenido ideológico de lo justo (que hace que una situación sea justa desde una perspectiva filosófica, pero injusta desde otra) y por la naturaleza heterogénea del espacio (que genera ventajas y desventajas espaciales ineludibles).

Los valores e ideologías dominantes en cada sociedad influyen la manera como se distribuyen socioespacialmente las oportunidades y las cargas del desarrollo y de vivir en sociedad. Por tanto, la localización (social, espacial, temporal, sectorial) de las oportunidades de bienestar, así como la selección de los sitios de intervención de política pública, son decisiones cruciales para lograr paisajes socioespaciales más justos —o menos injustos - en el mundo real (Soja, 2009: 3). Aquí proponemos a la accesibilidad (potencial y real: Joseph y Phillips, 1984) como el nodo conceptual y operativo que espacializa la medición de las CRV. Sin embargo, ¿qué se entiende por accesibilidad?

\section{Accesibilidad: elemento clave para medir las CRV}

El concepto de accesibilidad ha sido abordado desde diversas disciplinas, pero no existe consenso general sobre su significado (Bath et al., 2000). Goodall (1987) elaboró una de las definiciones más sencillas y utilizadas:

"accesibilidad es la facilidad con la que se puede alcanzar un cierto sitio (destino), desde otros puntos en el territorio (orígenes), por lo que sintetiza las oportunidades de contacto e interacción entre determinados orígenes y destinos". La definición de Goodall es probabilística y agregada (Campos y Garrocho, 2018).

Johnston et al. (2000) van en el mismo sentido, ya que establecen que la "accesibilidad es la oportunidad de interacción y contacto entre orígenes y destinos". 6

La accesibilidad es uno de los componentes más importantes para comprender la Justicia Espacial. Su estimación puede hacerse a diversas escalas y facilita el análisis de las ventajas/desventajas que pueden tener ciertas unidades territoriales respecto a otras, en términos de sus posibilidades para acceder a las oportunidades de bienestar. Fallas de accesibilidad a escala de ciudad (o de barrio), es decir, la falta de correspondencia entre la estructura del espacio urbano y los requerimientos de la población, generan disfunciones que pueden considerarse fallas de calidad urbana. ${ }^{7}$

\footnotetext{
${ }^{6}$ Cuando el concepto se aplica a servicios, se destacan dos aspectos: el primero, habla de las oportunidades (o probabilidades) de contacto e interacción, y se denomina accesibilidad potencial, diferente a la utilización efectiva del servicio, que se le llama accesibilidad real (Joseph y Phillips, 1984).

${ }^{7}$ La calidad urbana la entendemos como la accesibilidad que tiene la demanda - o un segmento de la demanda - localizada en cierta parte de la ciudad, a la oferta de servicios disponibles
} 
Inclusión de la variable espacial en la medición de las condiciones relativas de vida en ciudades ... / J.CAMPOS ALANÍS et al.

Estas fallas pueden referirse tanto a oportunidades que ofrece el sector público como el privado: desde hipermercados hasta bancos y oficinas gubernamentales; desde hospitales y farmacias hasta instalaciones educativas de todos los niveles; desde subcentros de empleo hasta panaderías, kioscos de periódicos y tienditas de la esquina; desde transporte público hasta amenidades aparentemente disponibles para todos como parques y jardines (Campos y Garrocho, 2018).

El patrón de asentamientos humanos a escala regional o el diseño urbano a escala intraurbana, pueden ser limitantes de la movilidad de las personas al momento de tratar de atender sus necesidades, y afectan de manera diferencial a ciertos grupos de la población, particularmente a aquellos con ingresos más reducidos y a la población más vulnerable (e.g. adultos mayores, personas con discapacidad, mujeres y niños).

La falta de correspondencia entre los patrones espaciales de la oferta y demanda de bienes y servicios reduce la calidad de vida de la población y por ende sus CRV. La razón: la accesibilidad está directamente relacionada con la calidad del consumo de servicios fundamentales para el bienestar, como los de salud, educación o abasto, por citar algunos (Garrocho, 2014). Por eso, consideramos que contar con un indicador de accesibilidad es clave para avanzar en la estimación de las CRV en un contexto de justicia espacial y calidad urbana.

Es necesario subrayar un elemento clave que está implícito en la accesibilidad: los costos de transporte que debe sufragar la población para utilizar los servicios. ${ }^{8}$ No son los mismos para todos y, por tanto, algunos grupos de población o áreas del territorio disfrutan o padecen (si se trata de servicios indeseables en proximidad: tiraderos de basura, terminal de autobuses) niveles diversos de exposición a beneficio y costos derivados de múltiples servicios públicos y privados. En conclusión, todos los cambios en la composición de la oferta y la demanda, como sus decisiones de localización espacial, afectan las oportunidades de acceso al bienestar de todos y sus CRV, especialmente de los más vulnerables. ${ }^{9}$

(enfoque de origen al destino o demanda-oferta). Sin embargo, también es posible medir con la accesibilidad el desempeño urbano (enfoque de destino al origen o enfoque oferta-demanda) y que permite estimar qué tan accesible es la oferta $-\mathrm{o}$ un segmento de la oferta - a la población: en otras palabras, que tan exitosa es una determinada localización o un patrón locacional (Garrocho y Campos, 2006).

${ }^{8}$ Como quiera que se estimen: en unidades de longitud, tiempo, monetarios, de energía; en términos objetivos o subjetivos (e.g. riesgo, incomodidad, peligro de acoso).

9 El tema va más allá de lo espacial. Influye lo social, en toda la extensión del término, pero también una serie de factores asociados (de oferta y demanda) que, en el caso de los servicios de salud, por ejemplo, pueden afectar la medición de la accesibilidad, por ejemplo: el horario del servicio, su calidad, los métodos de atención, el sexo del personal, la capacidad de atención, el tamaño de la unidad, el costo del servicio (por el lado de la oferta); y por el lado de los usuarios 


\section{Materiales y MÉTODo}

\section{Zona de estudio, fuentes de información utilizada y unidades espaciales}

Para demostrar la bondad de nuestro Método Socioespacial de Medición de CRV seleccionamos la Zona Metropolitana de Toluca (ZMT). La ZMT estaba integrada en 2010 por 15 municipios del Estado de México y sumaba 1.93 millones de habitantes (CONAPO, 2012). Es la quinta ciudad más poblada de México, se encuentra localizada en la región centro de México (Figura 1) y tiene una extensión de dos mil 182.8 kilómetros cuadrados.

Para estimar la demanda en el territorio de los servicios considerados en este trabajo, se utilizó el Censo de Población y Vivienda 2010 a una escala de desagregación de sección electoral (INEGI-IFE, 2010), que es uno de los niveles de desagregación de la información censal con mayor detalle que hay en México y que, además, permite contrastar los ámbitos urbano y rural con unidades espaciales comparables en términos de tamaño de población. La ZMT en 2010 incluía 641 secciones electorales. ${ }^{10}$

La oferta de servicios se estimó con información del Directorio Estadístico Nacional de Unidades Económicas 2015 ${ }^{11}$ (conocido como DENUE: INEGI, 2015), que registra todas las unidades económicas que existen en el territorio nacional, incluyendo su localización espacial con coordenadas geográficas y el número de trabajadores por rangos. Se utilizó el personal ocupado por unidad económica como indicador de atractividad de los servicios, sobre el supuesto de que, a mayor número de empleados, mayor capacidad de atención y, por tanto, mayor atractividad. Esta es una práctica común en estudios de planeación de servicios públicos y privados (Cliquet, 2006; Simmons et al., 2017).

estaría la localización de la vivienda y del empleo, el ingreso, educación, valores culturales, edad, sexo, percepciones, expectativas, creencias (Garrocho, 1995).

${ }_{10}$ En el año 2005 el Instituto Federal Electoral y el Instituto Nacional de Estadística y Geografía, diseñaron un producto cartográfico denominado "Estadísticas Censales a Escalas Geoelectorales del II Conteo de Población y Vivienda 2005", donde se combinó la delimitación de las secciones electorales con la información censal. El aporte de dicho producto fue que por primera vez en un solo producto cartográfico se tenía información de los ámbitos urbano y rural construido a partir de unidades espaciales relativamente homogéneas en términos de electores y considerando los límites político-administrativos de los municipios y distritos electorales (INEGI-IFE, 2005). 11 El INEGI realiza los censos económicos cada cinco años y generalmente no coinciden con los censos de población y vivienda. Se eligieron los datos del censo económico del 2015 que en realidad se levantó en el 2014, por considerarse de mejor calidad que los emitidos en el 2009, año en que se publicó la primera versión del DENUE y donde se identificaron una serie de errores en la información. 
Inclusión de la variable espacial en la medición de las condiciones relativas de vida en ciudades ... / J.CAMPOS ALANÍS et al.

Figura 1: Localización geográfica de la Zona Metropolitana de Toluca

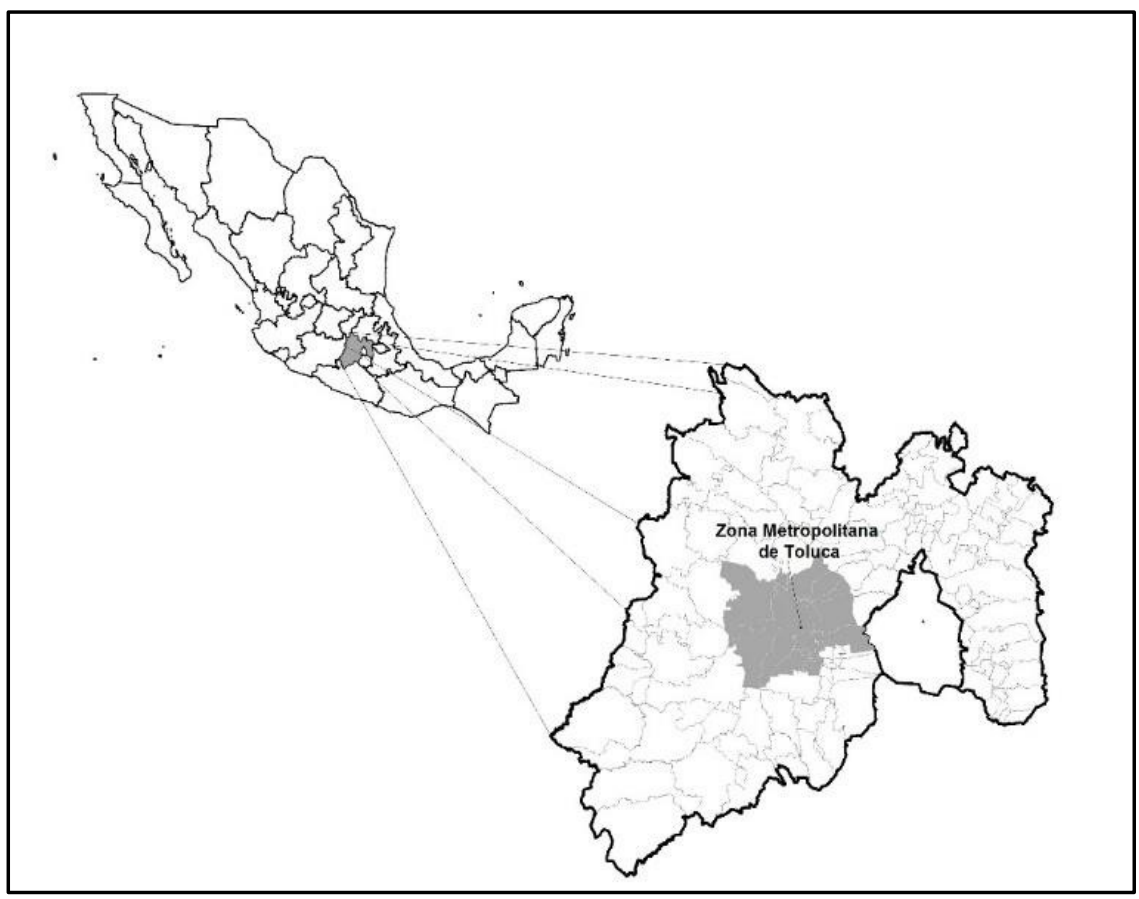

Fuente: elaboración propia a partir de INEGI-INE, 2011.

\section{Accesibilidad: método de estimación}

La explicación del cálculo de la accesibilidad a unidades de servicio se presenta con cierto detalle, porque es un punto clave de nuestra propuesta para generar mediciones socioespaciales de las CRV. ${ }^{12}$ Aquí, nuestras estimaciones y análisis se apoyan en datos sobre: i) la capacidad de los servicios (e.g. la magnitud de la oferta); ii) la magnitud de la demanda (e.g. información sobre la población objetivo que es usuaria potencial de los servicios); y, iii) la localización espacial de la oferta y la demanda, para considerar los costos de transporte que deben sufragarse para que oferta y demanda se interrelacionen en el espacio (Knox, 1978; Handy, 1993; Verroen y Hilbers, 1996; Garrocho y Campos, 2006).

Existen diversos tipos de indicadores de accesibilidad potencial (Campos y Garrocho, 2018). Para los propósitos de este trabajo, se reto-

12 Para una explicación mucho más completa, los interesados pueden referirse a Garrocho y Campos (2006) que incluye un Anexo Metodológico con un ejemplo "paso a paso". 
ma la definición de Garrocho y Campos (2006: 354) que considera la accesibilidad como "el potencial de interacción entre la población objetivo que reside en cada unidad espacial (e.g. municipio, sección electoral, colonia, barrio, manzana) que integra un territorio y ciertas unidades de servicio". Esta definición se traduce en términos operativos como:

$$
A c c=\sum_{i=1}^{j} \frac{\frac{I_{j}}{P o b_{u p}}}{d i j^{b}}
$$

Donde:

- $\quad \mathrm{Acc}=$ Indicador de accesibilidad potencial

- $\mathrm{I}_{\mathrm{j}}=$ Atractividad de las unidades de servicio medida por el número de empleados de cada servicio analizado.

- $\quad \mathrm{Pob}_{\mathrm{UP}}=$ Población que es usuaria potencial de los servicios, que para el ejercicio, es toda la población residente de la ZMT que demandaría un determinado bien o servicio.

- $\mathrm{D}_{\mathrm{ij}}=$ Distancias lineales entre el centroide de cada sección electoral $i$, consideradas como los lugares de residencia de la población usuaria (origen) y las unidades de servicio (destino) $j$. Se eligió usar la distancia lineal por su facilidad de cálculo, sin embargo, puede ser reemplazable por la distancia por la red vial, el tiempo de traslado o los costos de transporte. ${ }^{13}$

- $\quad b=$ Parámetro que refleja la sensibilidad de los usuarios potenciales ante cambios de los costos de transporte. Es decir: la reducción o aumento de la utilización de los servicios por parte de los usuarios ante cambios en los costos de transporte. A este parámetro se le conoce como fricción de la distancia. En este trabajo, por facilidad en la exposición se utiliza $b=1.0 .{ }^{14}$

13 Existen estudios que han demostrado que, en grandes ciudades, los resultados al estimar la accesibilidad por diferentes métodos (distancia lineal, distancia por la red vial y tiempo de traslado) son muy similares pues al correlacionar los resultados de cada método el coeficiente es de 0.95 (Aparicio et al., 2008). Para el caso de la ZMT, la correlación entre la distancia lineal y la distancia por la red de vialidades en la ZMT es de 0.87 , por lo que no vale la pena encarecer y complicar innecesariamente el análisis considerando la distancia a lo largo de la red de vialidades. Esto sólo nos conduciría al "espejismo de la exactitud", tan común en el medio académico, pero que limita seriamente considerar la accesibilidad en las operaciones cotidianas de los gobiernos locales y las empresas (Garrocho et al., 2017).

14 Este parámetro se puede estimar empíricamente. Ver un ejemplo detallado en Garrocho (1995), donde se estiman los parámetros para hospitales, clínicas y consultorios de la ZMT. 
Inclusión de la variable espacial en la medición de las condiciones relativas de vida en ciudades ... / J.CAMPOS ALANÍS et al.

La expresión $\left(\mathrm{Ij} / \mathrm{Pob}_{U P}\right)$ es un indicador de disponibilidad no-espacial muy utilizado, incluso por organismos internacionales, y no es otra cosa más que una medida de servicios disponibles per cápita en la zona de estudio, en un contexto en el que los costos de transporte fueran irrelevantes. Pero como no lo son, y menos cuando los servicios se ofrecen de manera gratuita o con un precio casi cero, entonces los costos de transporte actúan como la barrera principal para acceder a las unidades de servicio. En el índice de accesibilidad este componente de disponibilidad es ponderado por el efecto de los costos de transporte $\left(d i j^{b}\right)$ en la intensidad de la demanda (e.g. la sensibilidad de la demanda ante variaciones en los costos de transporte).

El índice de accesibilidad es sensible a cambios en la magnitud de la oferta y la demanda del servicio, la distancia o los costos de transporte entre orígenes y destinos, y la sensibilidad de los usuarios ante cambios en los costos de transporte. Este indicador ha sido ampliamente probado para medir la accesibilidad de servicios en ciudades de México y Latinoamérica (Campos y Garrocho, 2018). ${ }^{15}$ Además, registra varias ventajas deseables en los indicadores de accesibilidad: a pesar de su sencillez muestra correlaciones importantes con otros indicadores de accesibilidad (Kwan, 1998); parte de un enfoque sistémico que considera simultáneamente todos los orígenes (que estarían compitiendo por los oportunidades de bienestar), los destinos y los costos de transporte (Drezner y Hamacher, 2001); ofrece información para explicar diversos procesos urbanos (Song, 1996); permite diferenciar la magnitud y localización espacial de la oferta y la demanda según su tipo, así como los costos de transporte medidos de diversas formas (Birkin et al., 2002); otorga la posibilidad de construir escenarios de accesibilidad de los servicios a diversas escalas espaciales (e.g. escala intraurbana y metropolitana) (Ghosh y McLafferty, 1987); es sólido en lo conceptual (Wilson, 1971); es fácil de calcular e interpretar (TDM, 2003) y genera información realmente útil para la toma de decisiones (Garrocho et al., 2017). ${ }^{16}$

${ }^{15}$ En abril de 2019 este índice aparecía en cerca de 70 publicaciones académicas.

16 Nuestra metodología no escapa al problema de la Unidad Espacial Modificable (Openshaw, 1984), ya que se asume que la población residente en cada sección electoral tiene la misma accesibilidad a los servicios. La única alternativa para escapar de este problema es considerar a cada individuo en lo particular, en lugar de trabajar con unidades espaciales, lo que sólo es práctico para análisis de escala micro (Kwan, 1998). 


\section{Dimensiones e indicadores considerados para estimar socioespacialmente las CRV}

Para demostrar las ventajas de nuestro método Socioespacial para medir las CRV sobre los enfoques tradicionales No-espaciales, optamos por realizar un análisis de contraste y posteriormente uno de integración. Son dos los objetivos: i) develar la superioridad de nuestro método de medición (que incluye la accesibilidad a los servicios) sobre los métodos No-Espaciales (tradicionales: el IDH y el IM) que sólo consideran la dotación del servicio (e.g. la cobertura administrativa); y ii) mostrar las ventajas de integrar ambos métodos.

\section{Dimensiones e indicadores del análisis de contraste: Método Socioespacial vs No-Espacial}

Para estimar las CRV se consideraron dos dimensiones comparables para ambos métodos: educación y salud. Estas dimensiones se integraron por siete indicadores espaciales y por cinco no-espaciales que se detallan en la Tabla 1. Nótese que todos los indicadores espaciales se refieren a la accesibilidad potencial a los servicios, estimada con el índice descrito previamente. Para el caso del método No-espacial, aplicamos el procedimiento del IM. Sus resultados, en este caso, son muy similares al del IDH, por lo que sería redundante presentar los resultados de ambos métodos tradicionales. ${ }^{17}$

Reiteramos: la elección de las dimensiones considera temáticas e indicadores lo más similares entre ambos métodos, a fin de lograr un buen contraste entre los resultados. Si se observa la Tabla 1, la columna relativa a los indicadores espaciales hace referencia a la accesibilidad potencial que tiene la población. Es decir, la oportunidad acumulada de utilización de cada unidad educativa y de salud, en cada nivel considerado. Por su parte, los indicadores No-espaciales sólo hacen referencia a una simple situación de cobertura administrativa, es decir, a si las personas disponen o no del servicio en términos normativos, sin hacer referencia al lugar donde se reciben dichos servicios: no consideran a los costos de transporte que les implica utilizar los servicios.

Como puede apreciarse, existe gran diferencia entre los enfoques y métodos. Sin embargo, como lo veremos más adelante, estas diferencias abren una gran ventana de oportunidad para complementarse. Sólo se requiere adoptar un enfoque integrado de oportunidad-cobertura para evaluar cada

${ }^{17}$ Con el fin hacer comparables las escalas de medición, se manejó el inverso de los indicadores del método IM, así reflejan la cobertura o disponibilidad de los bienes y servicios. 
Inclusión de la variable espacial en la medición de las condiciones relativas de vida en ciudades ... / J.CAMPOS ALANIS et al.

sección electoral y así estar en posibilidad de hacer recomendaciones más informadas para el diseño de políticas públicas.

Tabla 1: Dimensiones espaciales e indicadores para la determinación de las CRV

\begin{tabular}{lll}
\hline Dimensión & \multicolumn{1}{c}{$\begin{array}{c}\text { Indicadores Espaciales } \\
\text { (oportunidad) }\end{array}$} & \multicolumn{1}{c}{$\begin{array}{c}\text { Indicadores no Espacial } \\
\text { (cobertura) }\end{array}$} \\
\hline & $\begin{array}{l}\text { Accesibilidad a escuelas } \\
\text { de preescolar }\end{array}$ & $\begin{array}{l}\% \text { de población de } 3 \text { a } 5 \text { años } \\
\text { que asiste a la escuela }\end{array}$ \\
& Accesibilidad a escuelas & $\%$ de población de 6 a 11 años \\
primarias & que asiste a la escuela \\
Educación & Accesibilidad a escuelas & años que asiste a la escuela \\
& secundarias & $\%$ de población de 15 a 17 \\
& Accesibilidad a escuelas & que asiste a la escuela \\
de nivel medio superior & $\%$ de población derechoha- \\
Accesibilidad a clínicas & biente a servicios de salud \\
Salud & Accesibilidad a hospitales & \\
generales públicos & \\
Accesibilidad a hospitales & \\
de especialidades & \\
\hline
\end{tabular}

Fuente: elaboración propia con base en los datos de los censos de población y económico del INEGI.

\section{Procesamiento de la información}

El procesamiento de la información espacial se realizó en el software ArcGis versión 10.2 y en la Estación de Inteligencia Territorial de El Colegio Mexiquense: CHRISTALLER ${ }^{\circledR}$ (Chávez y Garrocho, 2018). Para el análisis estadístico se utilizó el software SPSS 23. La estratificación de los datos se apoyó en el método Natural Breaks, que agrupa los datos por la similitud de un atributo y maximiza la diferencia entre los grupos.

\section{Análisis de resultados: contraste entre el Método Socioespacial y el No-Espacial}

Debido a que no disponemos de espacio suficiente para comparar todos los indicadores elegidos de las CRV para ambos métodos, optamos por contrastar, a manera de ejemplo, los resultados de la dimensión salud. En el Método Socioespacial utilizamos el indicador accesibilidad de la pobla- 
ción a las unidades médicas de primer nivel en la ZMT (indicador espacial), mientras que en el Método No-Espacial utilizamos el indicador derechohabiencia (indicador administrativo o normativo) a los servicios de salud. Finalmente, con el método de componentes principales, construimos un indicador agregado oportunidad-cobertura de las CRV a escala metropolitana y los comparamos. Con esto es suficiente para alcanzar los objetivos de este trabajo.

\section{Comparación de la dimensión salud}

Para realizar el contraste de la dimensión Salud, se mapeó la información de cada método (Socioespacial y No-Espacial). Tanto la accesibilidad como la cobertura normativa se graduaron en cinco rangos: muy bajo, bajo, medio, alto y muy alto, donde muy bajo representa la situación más inconveniente y muy alto la más conveniente. Los resultados registran contrastes muy interesantes.

En la Figura 2a se representa el comportamiento de la accesibilidad a clínicas de primer nivel disponibles en la ZMT. Se observa claramente un patrón centro-periferia, debido a que la localización de las unidades de servicios de salud ha favorecido el centro de la ZMT (particularmente los municipios de Toluca y Metepec), así como algunas áreas periféricas que corresponden a cabeceras municipales y localidades de mayor población. El mapa muestra claramente la ventaja que tiene la población residente en las áreas más pobladas, por su mayor proximidad a los equipamientos. En contraste, el Método No-Espacial (que valora la dimensión salud a partir del dato administrativo de derechohabiencia), presenta una distribución mucho más homogénea en el territorio de los rangos muy alto y alto, que no se corresponden con la localización de las unidades de servicio. De hecho, llama la atención la cantidad de secciones electorales periféricas que, sin contar con clínica alguna, se encuentran entre las secciones con mejor cobertura, incluso por arriba de aquellas localizadas en los municipios centrales (Figura 2b).

Mientras los resultados del Método Socioespacial se derivan de la distribución geográfica de la oferta y la demanda en el territorio intrametropolitano, los del Método No-Espacial se desprenden solamente de la localización de los derechohabientes, sin tomar en cuenta su relación espacial con la ubicación de las unidades de servicio. Por eso, los rangos Bajo y Muy Bajo del Método No-Espacial incluyen mucho menos secciones electorales que en el Método Socioespacial. 
Inclusión de la variable espacial en la medición de las condiciones relativas de vida en ciudades ... / J.CAMPOS ALANÍS et al.

Figura 2a: Accesibilidad potencial a las clínicas de primer nivel (A) y derechohabiencia a los servicios de salud (B) en la ZMT

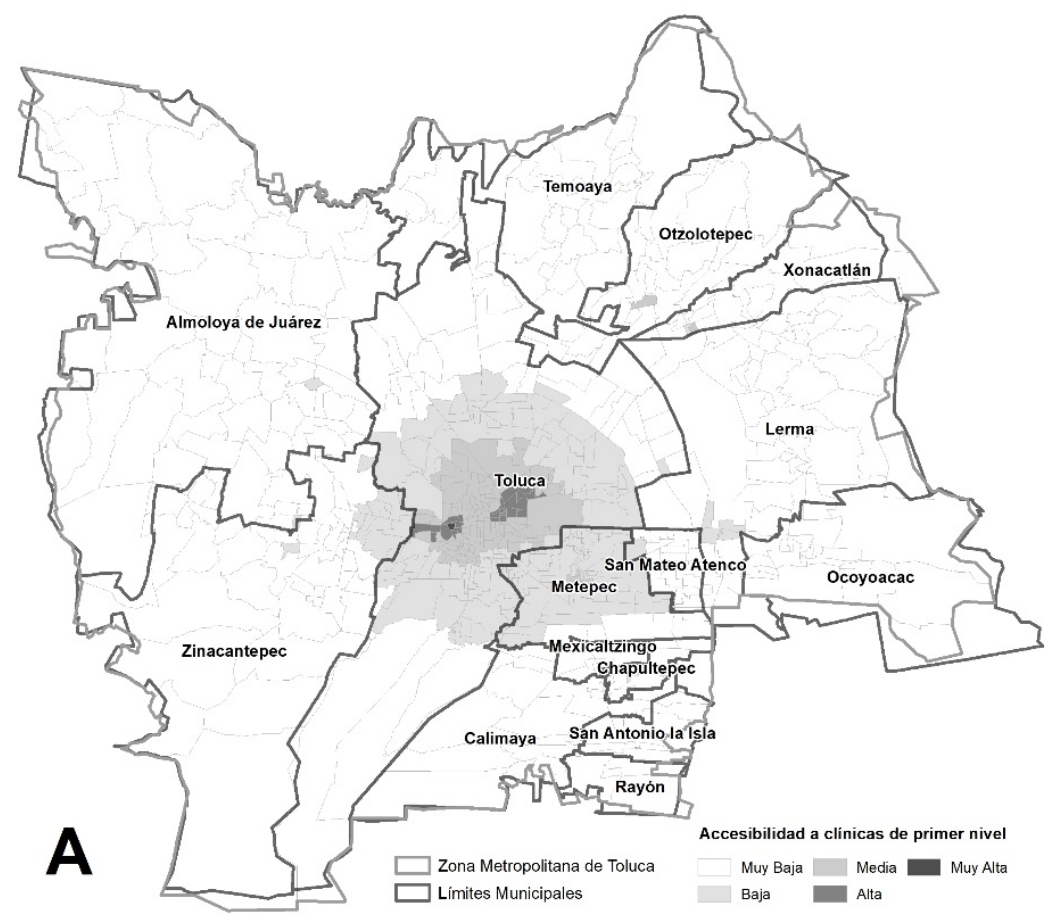

Fuente: elaboración propia con base en los datos de los censos de población y económico del INEGI.

Por tanto, el Método No-Espacial sesga los resultados en las estimaciones gubernamentales de CRV, ya que reduce notablemente las secciones electorales de los rangos Bajo y Muy Bajo. Nótese que esto es un artificio metodológico de las estadísticas oficiales, porque la medición resulta de un dato administrativo/normativo, no de un indicador que represente genuinamente la interrelación de la oferta y la demanda en el territorio (e.g. las oportunidades de utilización del servicio).

Los resultados del Método Socioespacial muestran, en cambio, que predominan los rangos de Baja y muy Baja accesibilidad (45.92 por ciento de las secciones electorales de la zona de estudio). 
Figura 2b: Accesibilidad potencial a las clínicas de primer nivel (B) y derechohabiencia a los servicios de salud (B) en la ZMT

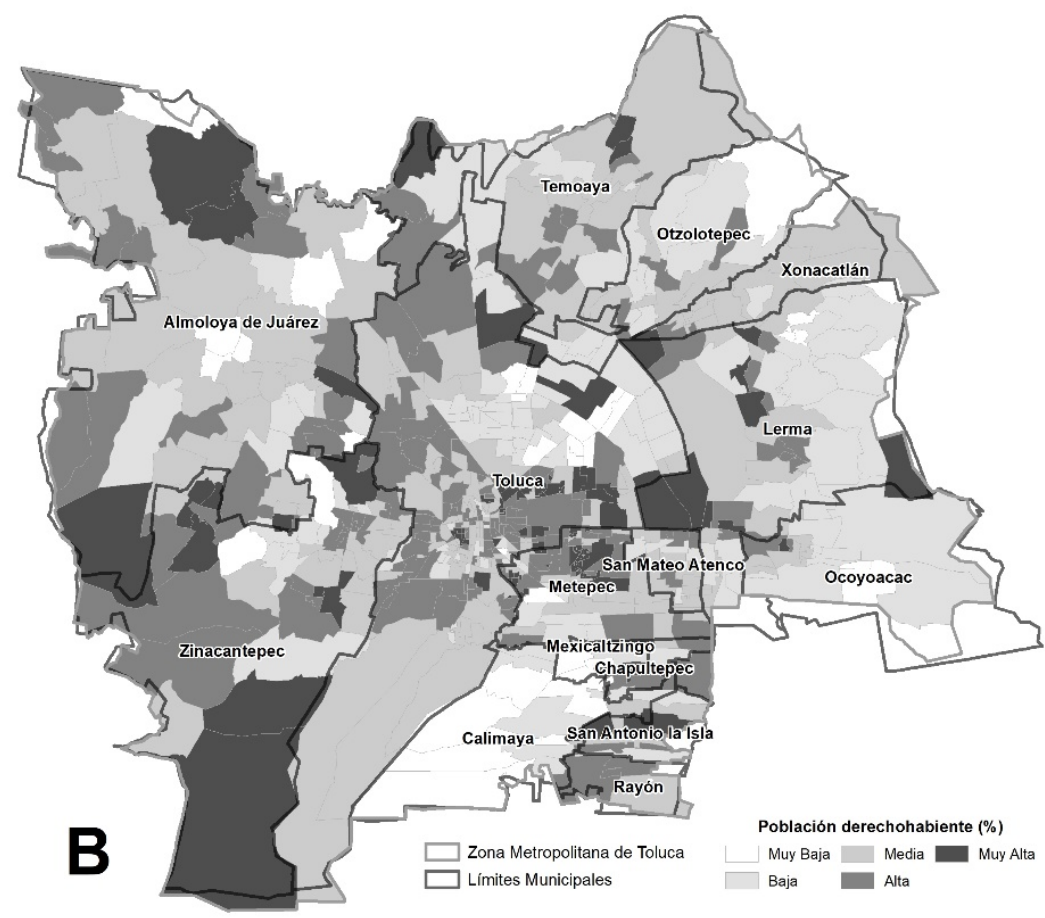

Fuente: elaboración propia con base en los datos de los censos de población y económico del INEGI.

El contraste es marcado: el Método No-Espacial indica que menos de seis por ciento de las secciones electorales registran Muy Baja cobertura y 20.34 por ciento califican como de cobertura Baja (Figura 3).

Es claro que existe una fuerte diferencia en cuanto a los resultados que arroja cada uno de los métodos. Para validarla, se realizó una estimación estadística mediante el método de correlación que arrojó una $\mathrm{R}^{2}$ de 0.012 , lo que indica que la relación entre los resultados de ambos métodos es casi nula. La razón es sencilla: los métodos miden cosas diferentes. El socioespacial mide oportunidades de acceso y utilización, el No-Espacial, mide simplemente cobertura normativa / administrativa en un no-lugar. 
Inclusión de la variable espacial en la medición de las condiciones relativas de vida en ciudades ... / J.CAMPOS ALANIS et al.

Figura 3: Porcentaje de secciones electorales según categoría de accesibilidad y derechohabiencia a los servicios de salud en la ZMT

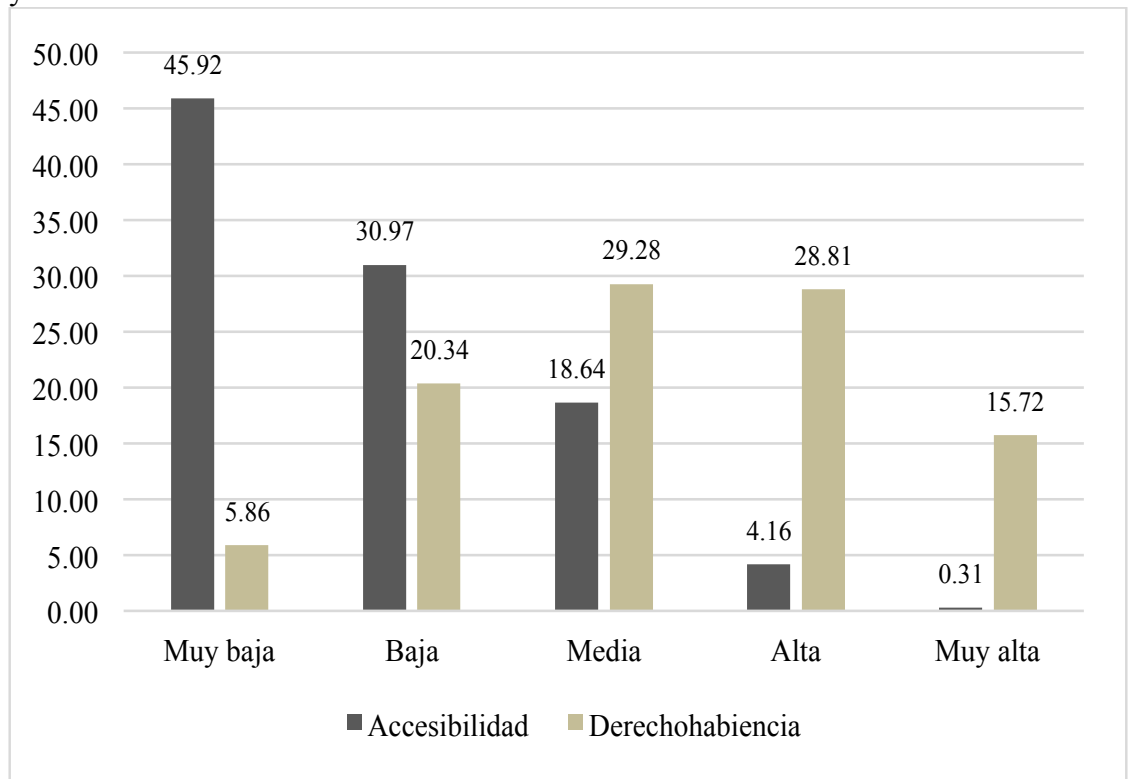

Fuente: elaboración propia con base en los datos de los censos de población y económico del INEGI

\section{Indicador Sintético de las CRV: Método Socioespacial vs Método No-Espacial y propuesta integrada}

Como el Método Socioespacial estima los niveles de accesibilidad de la población derechohabiente al sistema de unidades de salud y el Método No-Espacial considera el porcentaje de la población que tiene derechohabiencia administrativa en cada unidad espacial, sería conveniente combinar ambos métodos para analizar simultáneamente tanto la cobertura (indicador No-Espacial) como la accesibilidad (e.g. oportunidad de utilización: indicador Espacial).

Como hemos observado, el Método Socioespacial de las CRV es más realista que el Método No-Espacial, en el sentido de que considera la localización espacial de los servicios con respecto a la demanda y no como producto de un registro administrativo que puede indicar el derecho a gozar un servicio, pero sin incluir los costos de transporte, que son claves para que usuarios y servicios interactúen en el territorio. Por tanto, proponemos integrar ambos métodos y generar un indicador sintético. Para ello, estimamos con cada uno de los enfoques y sus respectivas dimensiones, un indicador síntesis de las CRV. 
Seleccionamos el Método de Componentes Principales, porque es uno de los más reconocidos para la construcción de índices compuestos en ciencias sociales. Las dimensiones e indicadores que incluimos se presentan en la Tabla $1 . .^{18}$

Al representar cartográficamente los resultados, se observa que el Método Socioespacial identifica 56.7 por ciento de las secciones electorales en la categoría de CRV Muy Bajas, seguida de la categoría Baja con 25.4 por ciento (Figura 4a). El Método No-Espacial es menos riguroso en la discriminación de los resultados (dada su menor variabilidad), pues solo 7.5 por ciento de las unidades espaciales se clasifican en la categoría Muy Baja, y 22 por ciento de la categoría Baja (Figura 4b).

Lo que marca la diferencia es que el Método Socioespacial incorpora los costos de interrelacionar la oferta y la demanda en el territorio (e.g. costos de transporte) y el Método No-Espacial simplemente lo ignora, como si la oferta y la demanda se interrelacionaran en un no-lugar. Esto se observa claramente en las zonas periféricas, que enfrentan las mayores desventajas de acceso y por tanto, de calidad de utilización (Ramos-Pérez y Garrocho, 2019) (Figura 5).

Además, debemos resaltar que el Método Socioespacial permite una mejor discriminación de las secciones electorales que no han sido dotadas de equipamientos y unidades de servicio. El Método No-Espacial no puede decir nada al respecto (Figuras $4 \mathrm{a}$ y $4 \mathrm{~b}$ ).

Los valores más altos del método Socioespacial conforman un claro patrón centro-periferia que parte de las zonas centrales de los municipios de Toluca y Metepec y se va degradando hacia el resto de los municipios, mientras que el método No-espacial, aunque también distingue una zona de atención clara, enmascara los cambios en los rangos de Muy Bajo a Muy Alto.

En la Figura 5 se observan claramente estas diferencias en términos de la agrupación de los resultados de cada método en las cinco categorías que hemos utilizado. Destacan las fuertes diferencias que generan los Métodos en las categorías Muy Baja y Baja.

\footnotetext{
${ }^{18}$ La elección de variables se considera adecuada para su síntesis cuando la suma de la varianza total explicada acumulada en el segundo factor es superior a 50 por ciento (Cadena, 2005, Peláez, 2017). En nuestro caso, para el Método Socioespacial se obtuvo una suma acumulada de 72.63 por ciento en el segundo factor y para el Método No-Espacial la suma acumulada fue 73.38 por ciento, por tanto, en ambos casos la elección de variables fue adecuada en términos estadísticos.
} 
Inclusión de la variable espacial en la medición de las condiciones relativas de vida en ciudades ... / J.CAMPOS ALANÍS et al.

Figura 4a: ZMT. Contrastes del indicador de CRV: Método Socioespacial (A) versus Método No-espacial (B)

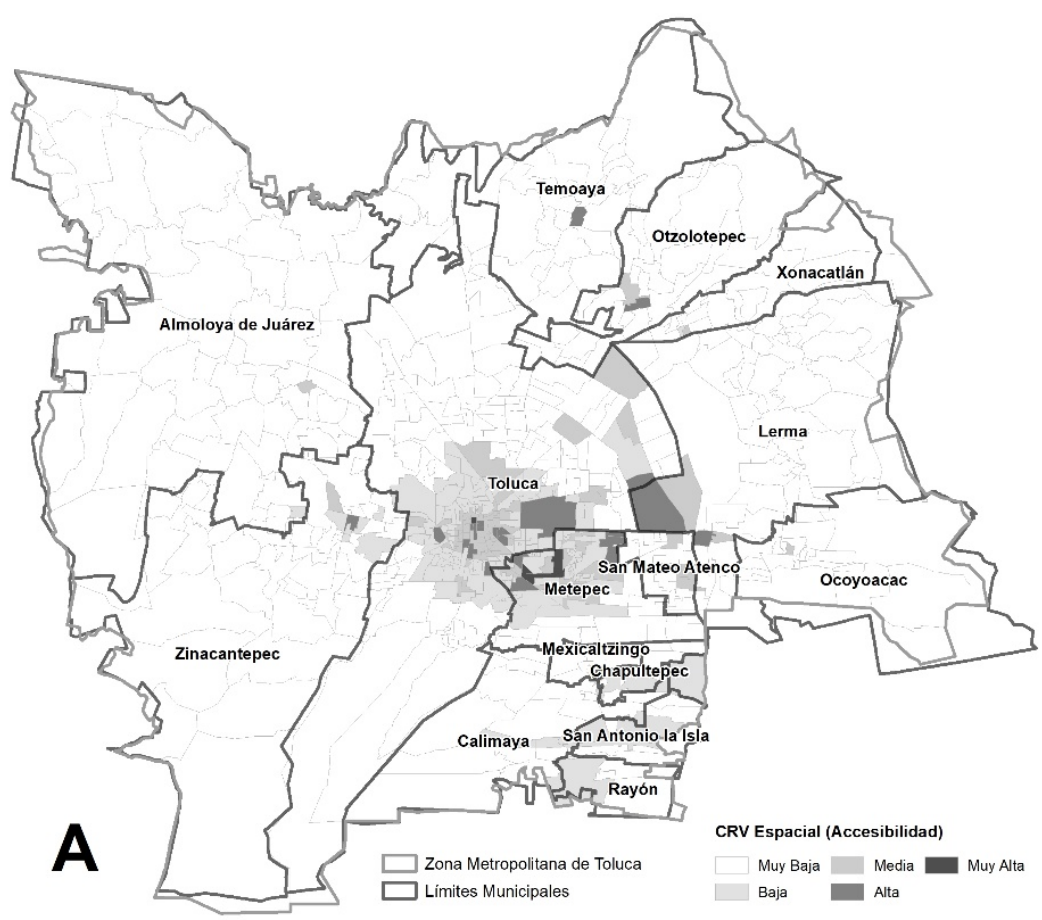

Fuente: elaboración propia con base en los datos de los censos de población y económico del INEGI.

De nueva cuenta, al realizar la correlación estadística entre los indicadores sintéticos considerando los valores de cada sección electoral, la $\mathrm{R}^{2}$ es 0.394, que indica lo débil de la similitud de los resultados entre ambos métodos. Adicionalmente se realizó una prueba de correlación espacial bivariada utilizando el indicador de Moran entre ambos métodos. ${ }^{19}$

19 En indicador bivariado de Moran es equivalente al indicador de correlación de Pearson, salvo que el primero considera como una variable más la vecindad de las secciones electorales. El segundo basa su estimación en el supuesto de independencia espacial. El IM puede analizarse desde dos formas, la global que reporta el comportamiento de todo el universo de datos analizados; y su forma local, que destaca las particularidades en ciertas zonas del universo de análisis. Esta variante local pertenece a la familia de Indicadores Locales de Asociación Espacial (LISA por sus siglas en inglés). 
Figura 4b: ZMT. Contrastes del indicador de CRV: Método Socioespacial (A) versus Método No-espacial (B)

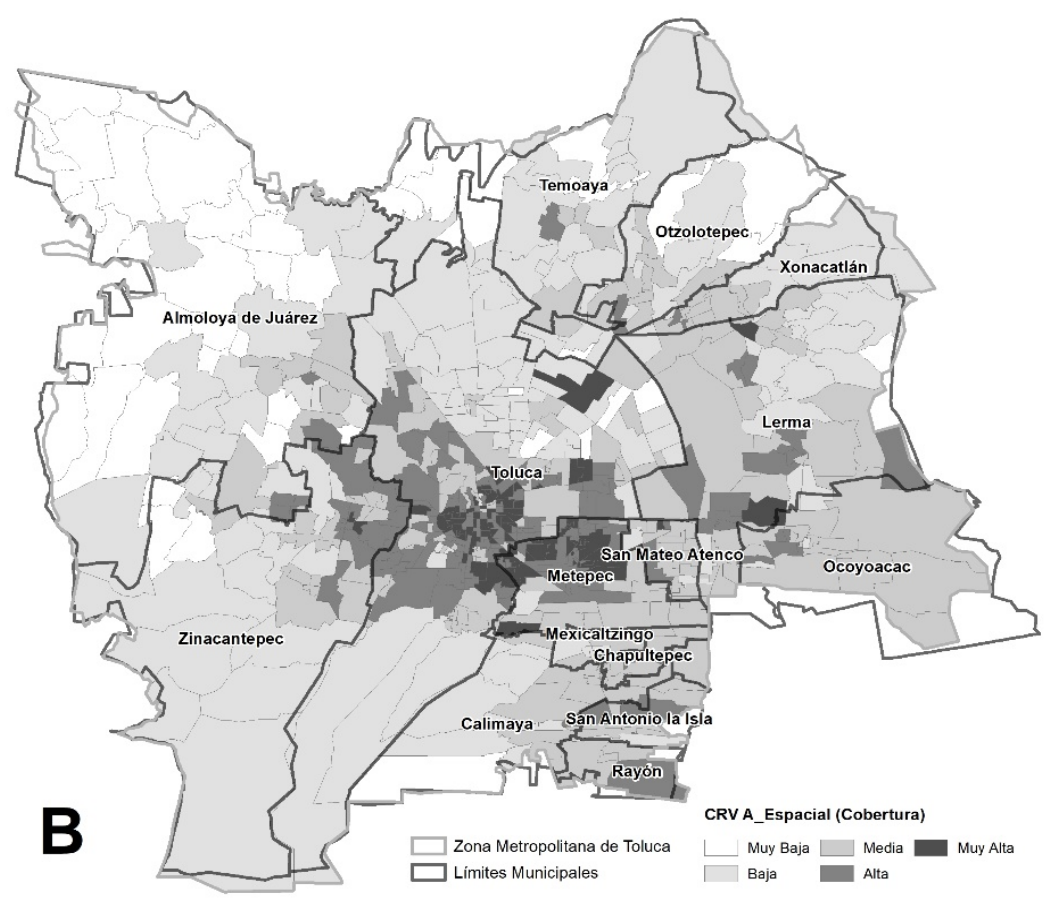

Fuente: elaboración propia con base en los datos de los censos de población y económico del INEGI.

El resultado fue 0.361. Al mapear los resultados se confirma un clúster en el centro de la ZMT, particularmente de los municipios de Toluca y Metepec, donde coinciden los valores altos de ambos enfoques, lo que explica que la correlación espacial bivariada no sea aún más baja (Figura 6).

Lo que sigue, es integrar un indicador resumen que conjugue los resultados de ambos métodos. El indicador resumen se muestra en la Figura 7, donde se mantiene la prevalencia del patrón centro-periferia descrito previamente, que se deriva del componente espacial del indicador. Destaca la relevancia del centro tradicional de negocios de la ZMT (integrado por las partes centrales de los municipios de Toluca y Metepec) donde se registran valores Altos y Muy Altos del indicador sintético de las CRV, lo que es consistente con otros estudios de accesibilidad y calidad urbana para la ZMT (Garrocho y Campos, 2010). 
Inclusión de la variable espacial en la medición de las condiciones relativas de vida en ciudades ... / J.CAMPOS ALANÍS et al.

Figura 5: ZMT. Porcentaje de secciones electorales según categoría de CRV de acuerdo con el Método Socioespacial y No-Espacial

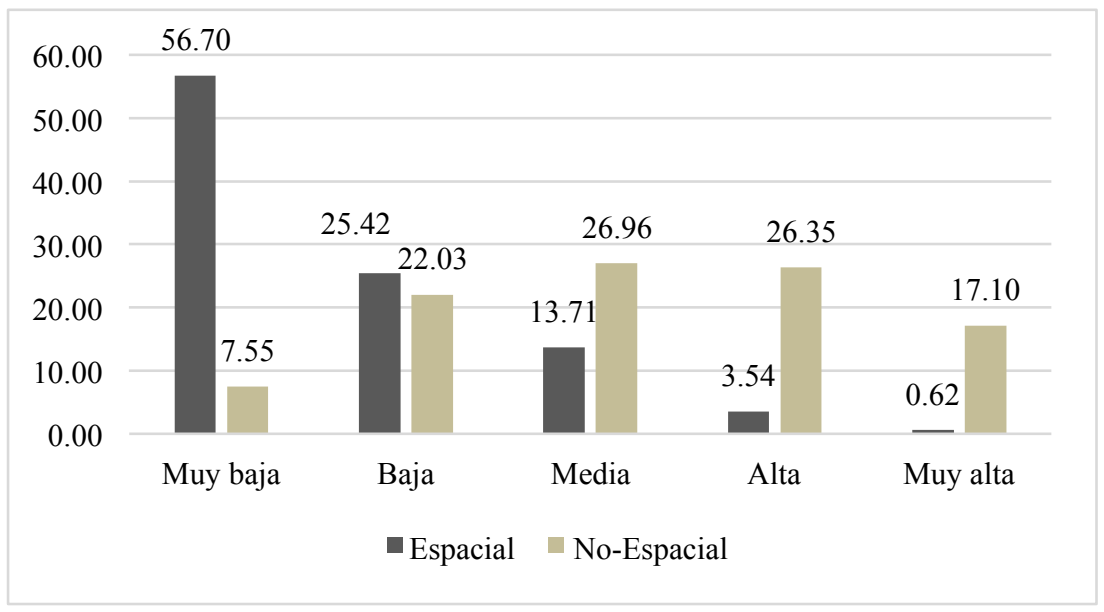

Fuente: elaboración propia con base en los datos de los censos de población y económico del INEGI.

Con estos resultados es posible afirmar que la situación beneficia principalmente a las zonas urbanas más consolidadas (las de mayor calidad urbana), sobre aquellas menos pobladas y con características rurales. Sin embargo, quizá sea más importante subrayar que nuestro método integrado elimina el sesgo aparentemente igualitario de la cobertura administrativa / normativa y genera como resultado la distinción entre unidades espaciales centrales, en transición, y periféricas, muy útil para el diseño de políticas de justicia espacial.

La importancia de la dimensión espacial confirma las desventajas de residir fuera del área urbana y la existencia de la trampa de la localización periférica (Garrocho, 2014; Garrocho y Campos, 2006). Los datos son contundentes: 59.5 por ciento de las secciones electorales registraron un indicador de CRV Muy Bajo y Bajo, mientras que menos de 14 por ciento registraron valores Altos y Muy Altos. Al aplicar el indicador de autocorrelación espacial local de Moran para identificar los agrupamientos espaciales por similitud y vecindad entre secciones electorales, se hace aún más evidente el patrón espacial centro-periferia. 
Figura 6: ZMT. Indicador bivariado de Moran de los métodos Socioespacial y No-Espacial

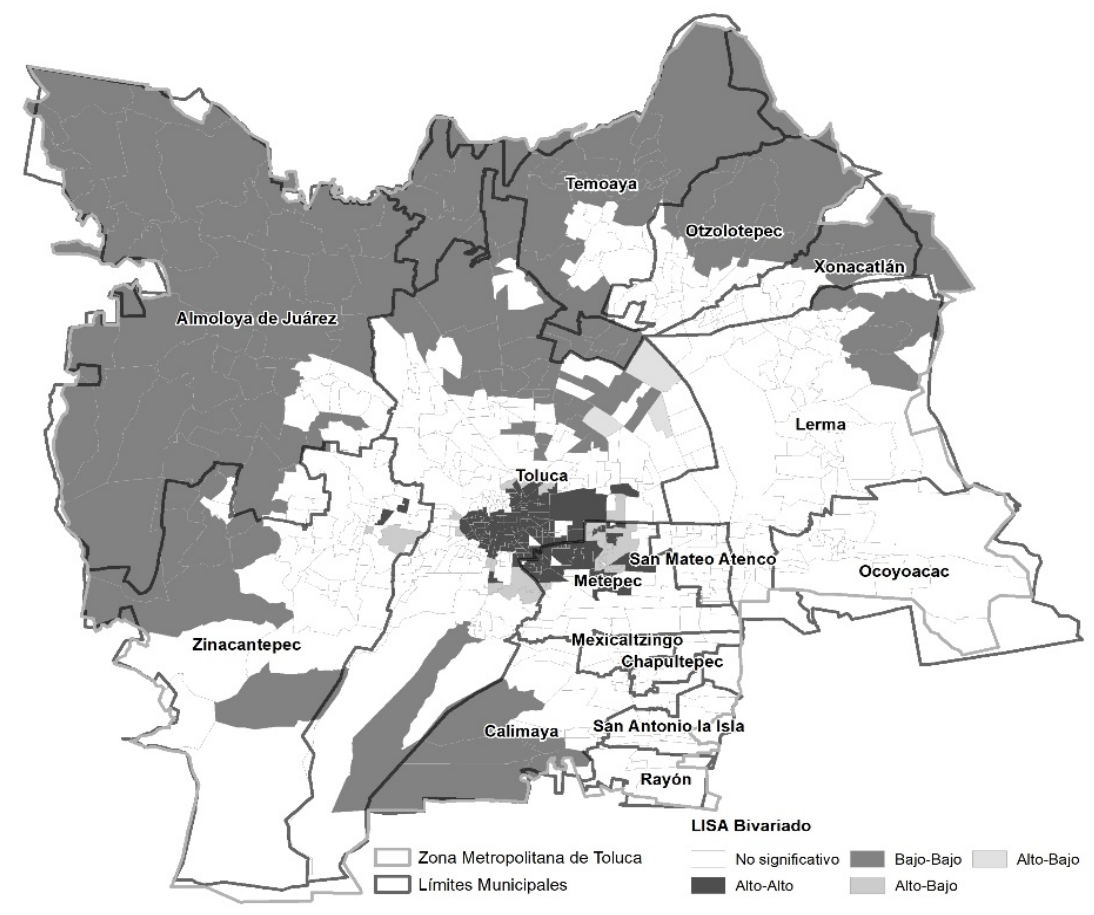

Fuente: elaboración propia con base en los datos de los censos de población y económico del INEGI.

El indicador de Moran destaca: i) la prevalencia de secciones que pertenecen a los centros tradicionales de negocios de los municipios de Toluca y Metepec (es decir, secciones electorales con valores altos del indicador integrado con vecinos en la misma condición: clusters Alto-Alto o ganadores); ii) una gran periferia con valores bajos y vecinos en la misma situación (clusters Bajo-Bajo o perdedores); y iii) algunas zonas en transición situadas al norte del municipio de Toluca con valores altos, pero con vecinos en condición marginal (clusters: Alto-Bajo o de notable desigualdad) (Figura 8). ${ }^{20}$

${ }^{20}$ Todos estos resultados son estadisticamente significativos al 95 por ciento. 
Inclusión de la variable espacial en la medición de las condiciones relativas de vida en ciudades ... / J.CAMPOS ALANÍS et al.

Figura 7: Indicador resumen de CRV en la ZMT

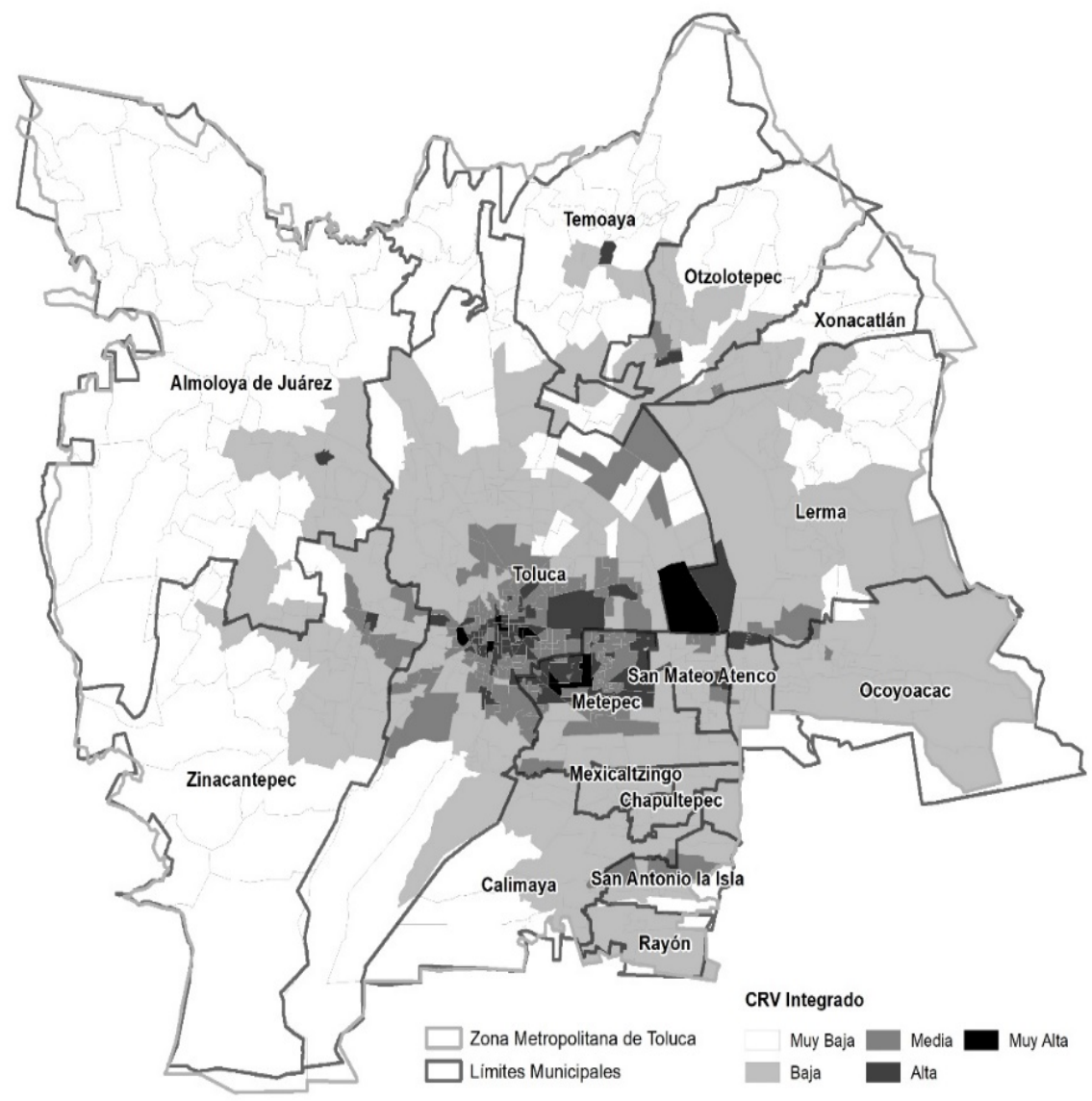

Fuente: Elaboración propia con base en los datos de los censos de población y económico del INEGI. 
Figura 8: Indicador de Moran de las CRV integrado en la ZMT

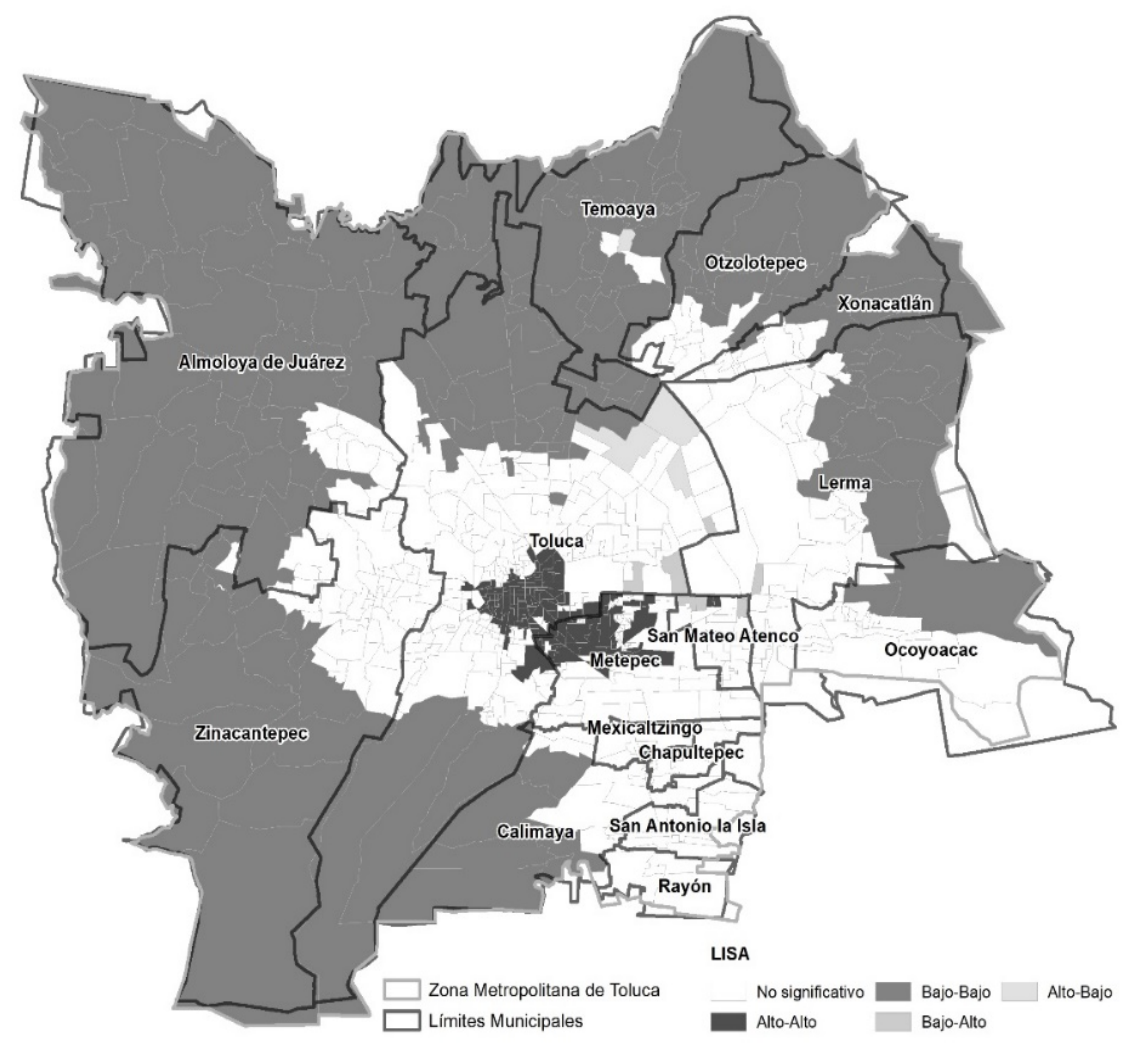

Fuente: elaboración propia con base en los datos de los censos de población y económico del INEGI

\section{ConClusiones}

La diferencia fundamental entre nuestro método Socioespacial para medir las CRV relacionadas con servicios de localización puntual y los No-espaciales puede resumirse así: no es lo mismo reportar que se tiene derecho normativo a un servicio (indicador No-espacial: derechohabiencia) que tener la posibilidad de hacer efectivo ese derecho mediante una buena calidad de utilización de las unidades de servicio por parte de la población (indicador Espacial: accesibilidad). El derecho normativo se decide por decreto, la posibilidad de hacer efectivo ese derecho depende en gran parte de que 
Inclusión de la variable espacial en la medición de las condiciones relativas de vida en ciudades ... / J.CAMPOS ALANÍS et al.

la planeación locacional de los servicios se haga con visión de calidad urbana y justicia espacial.

Al final, la cobertura del servicio, que es lo que considera el Enfoque No-Espacial, puede ser ilusoriamente incrementada mediante una intensa campaña que incorpore administrativamente población a los servicios (algo así como lo que sucedió en México con el Seguro Popular), pero eso no garantiza que la población tenga accesibilidad a los servicios y logre una buena calidad de utilización. En cambio, nuestro Enfoque Socioespacial se fundamenta en que sólo se pueden mejorar los dos puntos mencionados, mediante: i) la construcción de nuevo equipamiento bien localizado; ii) aumentando la capacidad instalada de las unidades de servicio existentes; y iii) mejorando la movilidad de la población o del servicio. Tremenda diferencia de implicaciones de política.

Nuestro método Socioespacial también tiene relevancia en términos de rendición de cuentas. Los informes y estadísticas gubernamentales utilizan el Enfoque No-Espacial por ignorancia o porque usualmente intentan resaltar logros aparentes, mientras que el Enfoque Socioespacial es mucho más riguroso y sus resultados son difíciles de manipular. Por esta misma razón tiene un alto potencial para el diseño de políticas urbanas y regionales que busquen una mayor justicia espacial en la asignación socioespacial de recursos públicos.

Como todos los métodos, el Socioespacial, puede tener una serie de limitaciones. Para este ejercicio, quizá la debilidad más significativa se relaciona con el uso de la distancia lineal como indicador de costos de transporte, aunque esto se puede corregir con un poco de tecnología y programación computacional. ${ }^{21}$ Así mismo se puede detectar el problema de la falacia ecológica, ya que se asume que toda la población de cada sección electoral tiene la misma accesibilidad a los servicios, pero este es un problema inherente de los estudios espaciales agregados (como lo es el de la Unidad Espacial Modificable) (Kwan, 1998; Openshaw, 1984).

Sin embargo, nuestro método tiene fortalezas relevantes: considera la accesibilidad a los servicios en lugar de una supuesta derechohabiencia administrativa determinada normativamente, entiende que el espacio es un agente activo en la distribución y redistribución de oportunidades de bienestar (lo que incide en la pobreza y la desigualdad), considera que la oferta y la demanda de servicios interactúan en el territorio, no implica cálculos complicados por lo que es sencillo de replicar y permite

21 La Estación de Inteligencia Territorial: Christaller $^{\circledR}$ de El Colegio Mexiquense ya está trabajando en esto (Chávez y Garrocho, 2018). 
combinar diversas fuentes de información (censos de población, cartografía y rutinas propias de los SIG). ${ }^{22}$ Estas características permiten generar medidas útiles de la accesibilidad a diferentes escalas: en el espacio micrometropolitano (incluso a escala de barrio y manzana) y del agregado metropolitano en su conjunto. Por tanto, es posible hacer comparaciones de las CRV entre ciudades o monitorear la evolución de una misma ciudad o zonas de la ciudad. Finalmente, nuestro método facilita hacer comparaciones entre unidades de servicio y simular escenarios de planeación (Garrocho y Campos, 2006; Campos y Garrocho, 2018).

La capacidad de nuestro método Socioespacial para explicar las desigualdades espaciales, ya sea como indicador unidimensional o como índice compuesto, supera con creces al Enfoque No-Espacial. Al comparar los resultados de ambos métodos, independientemente de que las variables analizadas no fueron idénticas, se demostró que el Método de Medición Socioespacial de las CRV permitió una mejor discriminación de las zonas con mayores desventajas, esto por la propia variabilidad espacial de los datos. Por otro lado, con ambos métodos los valores de las CRV Altos y Muy Altos se relacionan con la calidad urbana en el espacio intrametropolitano y siguen un patrón centro-periferia: de las áreas más consolidadas hacia los alrededores. Sin embargo, en las zonas de transición hacia la periferia, el método Socioespacial espacial distingue con mayor claridad las zonas con menor calidad urbana, lo que confirma la superioridad del Método Socioespacial sobre el No-espacial y pone de manifiesto las ventajas de su integración, para mejorar la calidad urbana y lograr mayor justicia espacial. Finalmente, y a modo de establecer una agenda de investigación que profundice en esta temática, habría que explorar otra vertiente de la distribución espacial de los equipamientos que impactan en las CRV, dado que, las zonas urbanas (que por su umbral de población) y concentración de estos equipamientos, tendrían siempre ventajas sobre zonas las rurales si se elige una escala regional, ${ }^{23}$ o bien, si se cambiase la escala a de AGEB, sección electoral, colonia o manzana, las zonas centrales superarían siempre a las periféricas. Sin embargo, en ninguno de los casos se incluyen las externalidades negativas o costos de aglomeración muy identificadas para las ciudades, tales como tráfico, la contaminación, las viviendas de menores dimensiones, y en general el costo de la vida, mientras que en contraste en las periferias suelen tener menores problemas, en otras palabras, incluir

22 En México las bases de datos son gratuitas, robustas y están disponibles para realizar análisis a diferentes niveles de desagregación territorial.

${ }^{23}$ Glaeser (2011) que plantea el éxito de las ciudades como los lugares donde se tienen mejores condiciones de vida, la población es más sana y tiene mejores condiciones de vida. 
Inclusión de la variable espacial en la medición de las condiciones relativas de vida en ciudades ... / J.CAMPOS ALANÍS et al.

esos aspectos negativos en la medición y que serían un valioso aporte en los métodos como los que fueron expuestos en este trabajo.

\section{REFERENCIAS BIBLIOGRÁFICAS}

Álvarez-Lobato, JA; Trujillo, A; Garrocho, C, 2018, "Multifuncionalidad urbana y adultos mayores en el Ârea Metropolitana de la Ciudad de México", en Investigaciones Geográficas, núm. 96, agosto.

Allingham, M., 2014, Distributive Justice, Routledge, NY.

Aparicio, P., Abdelmajid, M., Riva, M., Sheamur, R., 2008, "Comparing alternative approaches to measuring the geographical accessibility of urban health services: Distances types and aggregation-error issues", in International Journal of Health Geographics, 7:7, disponible en: http://www.ij-healthgeographics.com. content/7/1/7

Bath, Ch., Handy, S., Kockelman K., y Mahmassani, H., 2000, Development of an urban accesibility index: literature review. Research Report number 7-4938-1, Center for Transportation Research, The University of Texas at Austin.

Bennholdt, T., 1981, "Marginalidad en América Latina: una crítica de la teoría", en Revista Mexicana de Sociología, vol. 43, núm. 3-4, pp. 1505-1546.

Birkin, M., Graham, C., y, Martin P., 2002, Retail Intelligence and Network Planning, John Wiley \& Sons, Nueva York.

Bosque, J., Díaz C., y Díaz M., 2002, "De la justicia espacial a la justicia ambiental en la política de localización de instalaciones para la gestión de residuos en la comunidad de Madrid”, en Boletín de la Real Sociedad Geográfica, t. CXXXVII-CXXXVII. España.

Bosque, J., Gómez, M. y Rojas, F., 2006, "Un nuevo modelo para localizar instalaciones no deseables: ventajas derivadas de la integración de modelos de localización-asignación y SIG”, en Cuadernos Geográficos, núm. 39, Universidad de Granada, España.

Brand, A., 2007, Restructuring social and spatial justice in dialectical time. Past, present, future, recuperado de http://ocw.mit.edu/NR/rdonlyres/Urban-Studies-and-Planning/11-469Spring-2007/Assignments/brand.pdf.

Bromberg, A., Morrow, G., y Pfeirffer, D., 2007, “Why spatial justice?”, in Critical Planning, UCLA, department or urban planning.

Cadena, E., 2005, Neoliberalismo y Desigualdad Social: modelo de análisis regional y cartográfico. Proyecto de investigación 1858/2004, Universidad Autónoma del Estado de México.

Campos. J., 2009, La geografía de la marginación: enfoque conceptual y metodológico alternativo para el caso de México. Tesis de Doctorado en Geografía. Universidad Nacional Autónoma de México. 
Campos, J. y Garrocho, C., 2018, "Desigualdad de acceso de la población adulta mayor a las áreas verdes en el Área Metropolitana de la Ciudad de México", en Aguilar y Escamilla (coord.). Dimensiones espaciales de la pobreza y exclusión social en ciudades mexicanas. México, IG/UNAM-Miguel Ángel Porrúa (en prensa).

Campoy, M., 2002, "Marginación y pobreza", en Revista del Ministerio de Trabajo y Asuntos Sociales, recuperado de http://www.mtas.es/es/publica/revista/numeros/35/estudio4.pdf

Castells, M., 1977, La cuestión urbana. México, Siglo XI.

Chávez-Soto, T., y Garrocho, C., 2018, "Estación de Inteligencia Territorial: Christaller $^{\mathbb{B} "}$, en GeoSig, año 10, núm. 10, pp. 29-50.

Cliquet, G., 2006, Geomarketing: Methods and strategies in spatial marketing. John Wiley and Sons, Londres, UK.

CONAPO, 2012, Delimitación de Zonas Metropolitanas de México 2010. México, D.F., CONAPO.

CONAPO, 2011, Índice de marginación por entidad federativa y municipios 2010. México, D.F. CONAPO.

COPLAMAR, 1982, Geografia de la marginación. Necesidades esenciales de México. México, Siglo XXI.

Drezner, Zvi y Horst W. Hamacher, 2001, Facility Location: Application and Theory, 34 Springer- Verlag, Nueva York.

Garrocho, C., 1995, Análisis socioespacial de los servicios de salud: accesibilidad, utilización y calidad. México. El Colegio Mexiquense-DIF Estado de México.

Garrocho, C., 1997, “Moral, técnica y servicios de salud”, en Ciudades, núm. 33, enero-marzo, pp. 59-64.

Garrocho, C. y Campos, J., 2006, “Un indicador de accesibilidad a unidades de servicio clave para ciudades mexicanas: fundamentos diseño y aplicación", en Economía, Sociedad y Territorio, vol. 6, núm. 22, pp.349-397.

Garrocho, C. y Campos, J., 2010, “Organización espacial del sistema bancario dentro de la ciudad: estrategia territorial, accesibilidad y factores de localización", en Economía, Sociedad y Territorio, vol. 10, núm. 33, pp. 413-453.

Garrocho, C., 2014, "Pobreza urbana en asentamientos irregulares de ciudades mexicanas: la trampa de la localización periférica", en Cabrero, E. (coord.). Ciudades Mexicanas. Desafios en concierto. Ed. Fondo de Cultura Económica.

Garrocho, C. y Campos, J., 2016, Segregación socioespacial de la población mayor en la Ciudad de México: la dimensión desconocida del envejecimiento. El Colegio Mexiquense, México.

Garrocho, C.; Chávez, T.; Álvarez-Lobato, A., 2017, “Accesibilidad de la población mayor a farmacias en el espacio intraurbano: desplazamientos caminando y 
Inclusión de la variable espacial en la medición de las condiciones relativas de vida en ciudades ... / J.CAMPOS ALANIS et al.

el método de área de cobertura flotante", en Figueroa-Monsalve, O.; de Freitas, A.; Valenzuela, L.M. (coords.), Transporte y Desarrollo Urbano, Pontificia Universidad Católica de Chile, Santiago, Chile.

Glaeser, E., 2011, Triumph of the city: how urban spaces make us human. London. England. McMillan.

Gervais-Lambony, P., 2007, Spatial justice. Disponible en http://www.h- net.org/ announce/show.cgi? ID $=155684$.

Goodall, B., 1987, The Penguin dictionary of human geography. Londres, Inglaterra, Penguin Books.

Ghosh, Avijit y McLafferty, Sara, 1987, Location strategies for retail and services firms, Lexington Books, Nueva York.

Handy, S.L., 1993, "Regional versus local accessibility: neo-traditional development and its implications for non-work travel", in Built Environment, 18(4), 253 267.

Harvey, D., 1973, Social justice and the city, University of Georgia Press, Athens, GA, USA.

INEGI-IFE, 2005, Estadísticas censales a escalas geoelectorales. Instituto Nacional de Estadística Geografía e Informática e Instituto Federal Electoral, México.

INEGI-IFE, 2010, Estadísticas censales a escalas geoelectorales. Instituto Nacional de Estadística Geografía e Informática e Instituto Federal Electoral, México.

INEGI, 2015, Directorio Estadístico Nacional de Unidades Económicas. Disponible en http://www3.inegi.org.mx/sistemas/descarga/?c=200

Johnston, R.J., Gregory, D. y Smith, D.M., 2000, The dictionary of human geography. Oxford, Inglaterra, Blackwell

Joseph, A.E y Phillips, D.R., 1984, Accessibility and utilization: geographical perspectives on health care delivery. Londres, Inglaterra, Harper and Row.

Kaztman, Rubén, 2005, "Activos, vulnerabilidad y estructura de oportunidades: enfoque AVEO”, en Canudas, R. D. C. y Lorenzelli, M., Inclusión social. Una perspectiva para la reducción de la pobreza, INDES, Tegucigalpa, Honduras, p.p. 54-77.

Kaztman, Rubén, 1999, Activos y estructuras de oportunidades: estudios sobre las raices de la vulnerabilidad social en Uruguay. PNUD-CEPAL, Montevideo, Uruguay.

Knox, P., 1978, "The intraurban ecology of primary medical care: patterns of accessibility and their policy implications", in Environment and Planning A, 10, 415-435. 
Kwan, M., 1998, "Space-time and integral measures of individual accessibility : a comparative analysis using a point-based framework", in Geographical Analysis, 30(3), 191-216.

Lefebvre, H., 1996, Writtings on cities. Oxford. Blackwell publishers.

Link, F., 2011, “Seeking spatial justice”, in EURE, vol 37, núm. 111, pp. 173-177.

London, S. y Santos, M., 2007, Desarrollo e instituciones precarias: la Argentina de los '90. Economía y Sociedad, vol. 12, no 20, pp. 129-158.

Openshaw, S., 1984, The modifiable areal unit problem. Geo Abstracts, University of East Anglia, Norwich, UK.

Peláez, O., 2017, "Deterioro de la capacidad de síntesis del índice de marginación: una propuesta de índices complementarios", en Paradigma Económico, año 9, núm.1, enero-junio.

Pérez, G., 2015, “Acessibilidad geográfica a los serviçios de salud: un estudio de caso para Barranquilla”, en Sociedad y Economía, 28: 181-208.

Pinch, S., 1979, "Territorial justice in the city: a case study of the social services for the elderly in Greater London", en D T Herbert y D M Smith (Eds.), Social Problems and the City. Oxford University Press, London, p.p. 201-223.

Pirie, G., 1983, "On spatial justice, in Environment and Planning A, vol. 15, nnúm. 4, pp. 465-473.

Pred, A., 1985, "The social becomes the spatial, the spatial becomes the social: enclosures, social change and the becoming of places", en Gregory, Derek y Urry, John. Social relations and spatial structures. Macmillan Education UK, 1985. p. 337-365.

Ramos-Pérez Daniel y Garrocho, Carlos, 2019, El envejecimiento demográfico y la importancia de la accesibilidad a servicios de salud para la población mayor, El Colegio de México, Documento no Publicado,

Rivas, D., 2012, "Explorando algunas trayectorias recientes de la justicia en la geografía humana contemporánea: de la justicia territorial a las justicias espaciales", en Cuadernos de Geografía: Revista Colombiana de Geografía, vol. 21, núm. 2, pp. 75-84.

Sánchez, A., 2000, Marginación e ingresos en los municipios de México. Análisis para la asignación de recursos fiscales. México, IIE/UNAM. pp 278.

Sen, A., 1996, La calidad de vida. México, Fondo de Cultura Económica.

Simmons, J., Garrocho, C., Kamikihara, S., y Campos, J., 2017, “The evolving retail structure of Mexico City", in Applied Economic Geography, (En prensa).

Smith, DM., 1994, Geography and Social Justice. Cambridge, MA: Basil Blackwell.

Smith DM., 1977, Human Geography: A Welfare Approach. Edward Arnold, Maidenhead, Berks, UK. 
Inclusión de la variable espacial en la medición de las condiciones relativas de vida en ciudades ... / J.CAMPOS ALANÍS et al.

Smith, DM., 1974, "Who gets what where, and how: a welfare focus for human geography”, in Geography, vol. 59, núm. 4, pp. 289-297.

Soja, E., 2014, En busca de la justicia espacial. Valencia, España, Tirant Humanidades.

Soja, E., 2009, “The city and spatial justice”, in Spatial Justice, vol. 1, núm. 1, pp. $1-5$.

Song, S., 1996, "Some tests of alternative accessibility measures: a population density approach", in Land Economics, 72 (4): 474-482.

TDM, 2003, TDM Encyclopedia. Victoria Transport Policy Institute, Victoria, Canadá.

Verroen, E.J. y Hilbers, H.D., 1996, Urban planning and mobility, some Dutch experiences. Institute for Transportation, Netherlands (Holanda).

Wilson, AG., 1971, “A family of Spatial Interaction Model, and Associated Developments", in Environment and Planning, 3: 1-32.

\section{RESUMEN CURRICULAR DE LOS AUTORES}

Juan Campos Alanís

Investigador Nacional Nivel II. Profesor de tiempo completo de la Facultad de Geografía de la Universidad Autónoma del Estado de México. Integrante del claustro de tutores de los posgrados que se ofertan en la facultad de Geografía; evaluador de proyectos CONACYT y Perfiles Deseables de la SEP; integrante externo de la comisiones dictaminadoras del Centro de Investigaciones en Geografía Ambiental de la UNAM; tutor externo de los posgrados en Geografía y Urbanismo de la UNAM, del posgrado de Estudios Urbanos de la Universidad Autónoma de Ciudad Juárez y docente externo del Programa de Maestría en Administración Electoral del IEEM. Colaborador del Programa Universitario de Estudios de la Ciudad (PUEC) de la UNAM. Integrante del proyecto Estación de Inteligencia Territorial: CHRISTALLER $\AA$.

Dirección electrónica: jcamposa70@gmail.com

Registro ORCID: https://orcid.org/0000-0002-5391-2447

\section{Luis Giovanni Ramírez Sánchez}

Catedrático CONACyT comisionado a El Colegio Mexiquense A. C. desde el 2016. Investigador Nacional Nivel Candidato. Integrante Externo de la Comisión Dictaminadora del Centro de Investigaciones en Geografía Ambiental de la UNAM y miembro del grupo de Tutores de la Maestría y Doctorado de la misma entidad. Evaluador de trabajos científicos en las 
revistas Perspectiva Geográfica (Colombia), Agricultura, Sociedad y Territorio (Colegio de Posgraduados) y Economía, Sociedad y Territorio (El Colegio Mexiquense A. C.). Profesor invitado en el CIGA-UNAM-Morelia, Universidad de Guadalajara y Universidad de Guanajuato. Miembro del seminario de investigación "Estudios Estratégicos del Estado de México", perteneciente a El Colegio Mexiquense A. C.

Correo electrónico: 1ramirez@cmq.edu.mx

Registro ORCID: http://orcid.org/0000-0003-0509-3413

\section{Carlos Garrocho}

Investigador Nacional Nivel III. Evaluador del Sistema Nacional de Investigadores (2015-2018). Profesor-Investigador en El Colegio Mexiquense (desde 1986). Fundador y Director de la revista Economía, Sociedad y Territorio. Integrante Externo de la Comisión Dictaminadora del Centro de Investigaciones en Geografía Ambiental de la UNAM. Integrante del Consejo Consultivo Estratégico del CentroMet. Integrante de la Junta de Gobierno de El Colegio Mexiquense. Ganador del Premio Estatal de Ciencia y Tecnología del Estado de México en 2011. Ganador del Premio "Arch C. Gerlach" en 2017, que otorga cada cuatro años la Organización de los Estados Americanos a "la obra original de mayor valor e importancia para el desarrollo de la geografía de América." Distinguido desde 2018 por el Gobierno de la República del Paraguay como asesor internacional del CONCYT-Paraguay. Coordinador General de la Estación de Inteligencia Territorial: CHRISTALLER ${ }^{\circledR}$. Integrante del Consejo Asesor Internacional de la revista EURE.

Dirección electrónica: cfgarrocho@gmail.com

Registro ORCID: https://orcid.org/0000-0001-9181-3151

Artículo recibido el 29 de abril de 2019 y aprobado el 8 de enero de 2020. 